\title{
Lessons from bacterial homolog of tubulin, Ftsz for microtubule dynamics
}

\author{
Rachana Rao Battaje and Dulal Panda \\ Department of Biosciences and Bioengineering, Indian Institute of Technology Bombay, Mumbai, India
}

Correspondence should be addressed to D Panda Email

panda@iitb.ac.in

\begin{abstract}
FtsZ, a homolog of tubulin, is found in almost all bacteria and archaea where it has a primary role in cytokinesis. Evidence for structural homology between FtsZ and tubulin came from their crystal structures and identification of the GTP box. Tubulin and FtsZ constitute a distinct family of GTPases and show striking similarities in many of their polymerization properties. The differences between them, more so, the complexities of microtubule dynamic behavior in comparison to that of FtsZ, indicate that the evolution to tubulin is attributable to the incorporation of the complex functionalities in higher organisms. FtsZ and microtubules function as polymers in cell division but their roles differ in the division process. The structural and partial functional homology has made the study of their dynamic properties more interesting. In this review, we focus on the application of the information derived from studies on FtsZ dynamics to study microtubule dynamics and vice versa. The structural and functional aspects that led to the establishment of the homology between the two proteins are explained to emphasize the network of FtsZ and microtubule studies and how they are connected.
\end{abstract}
Key Words
- FtsZ assembly
- microtubules
- cell division
- anticancer drugs
- antibacterial drugs

\section{Introduction}

Microtubules are major cytoskeletal protein structures of the eukaryotic system involved in cell division forming the primary components of the mitotic apparatus. Microtubules also form flagellar and ciliary structures for cell transport, maintain the cell polarity and are involved in cell signaling (Nogales 2001). Defective microtubules would lead to abnormal morphology of the cell and ultimately cell death if the division machinery is impaired. Microtubules are made up of protofilaments of tubulin subunits, which assemble to form the highly dynamic structures. Microtubule assembly is a highly complex process that has been studied for the past five decades and yet, so many mysteries are to be unraveled. However, numerous studies have made significant progress in understanding the mechanism of assembly and the various associating factors that play important roles in it.

Microtubules play a significant role in metaphase and anaphase of mitosis. They are the key components of the mitotic spindle apparatus, which is responsible for the segregation of chromosomes (Kline-Smith \& Walczak 2004, Kwon \& Scholey 2004). During the metaphase, the plus ends of microtubules undergo elongation and shortening for probing and binding to the kinetochores. This is called 'search and capture' function (Rieder et al. 1986). The chromosomes are then translocated to the equatorial plane, during which, the highly dynamic microtubules are stabilized to separate the chromosomes 
in the following anaphase (Higuchi \& Uhlmann 2005). Chromosomes get pulled toward the poles due to the shortening of microtubules (Rieder et al. 1994). This entire process is dependent on the dynamicity of microtubules and an obstruction would lead to the arrest of the cell division at the spindle checkpoint (Logarinho et al. 2004). Thus, agents that target the microtubules and hamper their dynamics can be potential anticancer, anti-fungal and anti-parasitic drugs (Jordan \& Wilson 2004, Singh et al. $2008 b$ ). The use of anti-microtubule agents as anticancer drugs has been studied extensively (Jordan \& Wilson 2004). In addition, it has been indicated that cell stress response is mediated by microtubules and their interacting partners (Parker et al. 2014). In several types of tumors, alterations in the expression of tubulin isotypes and microtubule-associated proteins and post-translational modifications have been observed (Parker et al. 2014). The understanding of signaling pathways and response mechanisms with respect to microtubules will help in designing new chemotherapeutic drugs.

Microtubule dynamics has been a subject of extensive research since the discovery of tubulin, yet, the mechanism is not fully understood. Complications in studying microtubules arise from the inability to express the protein in bacterial expression systems. Posttranslational modifications of tubulin are not possible inside bacterial cells due to the lack of chaperones and protein co-factors. Thus, the extraction and isolation of tubulin from eukaryotic cells like yeast is the preferred method of purifying the protein. This triggered the search for the homolog of tubulin in prokaryotes.

Many bacterial species such as cyanobacteria, azotobacteria, mycoplasmas, enteric bacteria and archaebacteria were found to contain cytoplasmic tubules, but whether or not these were related to microtubules and tubulin was a question of interest (Bermudes et al. 1994). About 20 years after the discovery of tubulin, FtsZ, initially thought to be the homolog of actin, arose as the candidate for being the tubulin homolog in prokaryotes (Erickson 1995). FtsZ is the first of several proteins that gets assembled at the division site in prokaryotes, to form the Z-ring, which is in association with other proteins forms the divisome (Margolin 2005). Over the years, numerous studies have been done on this bacterial cell division protein and several reports indicated striking similarities as well as differences between FtsZ and tubulin.

Since the discovery of FtsZ, studies on FtsZ dynamics have influenced the study of microtubule dynamics and vice versa. In this review, we focus on the similarities and differences between the two proteins, believed to have a common ancestor. Structural aspects have been covered in the first section. The dynamics of the two proteins have been compared in the following section. In the next section, some proteins belonging to FtsZ/tubulin superfamily, which act as connecting links between the two proteins have been mentioned. A section on microtubule-targeting agents and FtsZ-targeting agents and a comparison of their binding sites has been included to emphasize the significance of such interrelated studies between FtsZ and microtubules.

\section{Discovery of FtsZ and establishing homology with tubulin}

Several genes in the fts regions of the E. coli chromosome were identified while studying the effects of DNA damage on cell such as the elongation of cells and the inhibition of division (Van de Putte et al. 1964). These genes were involved in causing filamentous growth, a property that was temperature sensitive (Van de Putte et al. 1964). One of the genes in the 2-min region of $E$. coli genome disrupted the septum formation when mutated (Hirota et al. 1968). This gene was later given the name fts $Z$ to separate it from the other fts genes of the region (Lutkenhaus et al. 1980). It was found to be the target of cell division inhibitor during SOS response in E. coli, which shed light on its central role in the cell (Hirota et al. 1968, Lutkenhaus \& Donachie 1979, Lutkenhaus et al. 1980, Lutkenhaus 1983).

FtsZ was first characterized as a cytoskeletal protein based on experiments that determined the location of the protein. It has been found to be uniformly distributed throughout the cell during the growth phase and to form a ring-like structure at the mid-position in the dividing cells (Bi \& Lutkenhaus 1991). An overproduction of FtsZ in cells using multicopy plasmids induced the formation of additional septa (other than the medial septa for cell division), which resulted in the production of minicells (Ward \& Lutkenhaus 1985). The ring structure formed by FtsZ was proposed to be involved in constricting the cell wall to form the septum (Erickson 1995). Even though the function of FtsZ was similar to actin (which forms the contractile ring and cleavage furrow in eukaryotes), the two proteins were not found to be homologous (Bi \& Lutkenhaus 1991).

A 7-amino acid segment conserved in FtsZ called the G-box motif (SAG)GGTG(SAT)G was also found to be conserved across tubulin from different species (Mukherjee et al. 1993). Another segment (KR)GXXXXG is present at the inverted P-loop region of the two structures (Hesse et al. 1987, Sternlicht et al. 1987,

Published by Bioscientifica Ltd. 
Mukherjee et al. 1993, De Pereda et al. 1996). These are related to the GTPase family sequence motif GXXXXGK(ST) (Bourne et al. 1991). The probable homology of FtsZ to tubulin triggered a series of experiments to test whether FtsZ showed similar biochemical properties as that of tubulin. FtsZ binds to GTP and hydrolyzes it to GDP, a property also observed with tubulin (de Boer et al. 1992, Erickson \& O'Brien 1992, RayChaudhuri \& Park 1992, Mukherjee \& Lutkenhaus 1998). This categorized these two proteins as GTPases but as a distinct family in the group. They had the unique property where GTPase activation was coupled to self-association of the proteins (Nogales et al. 1998a).

Yet, the sequence homology between the two proteins was found to be low. Secondary structure prediction studies involving 200 tubulin sequences from different eukaryotic species and 12 FtsZ sequences demonstrated that tubulin is indeed homologous to FtsZ, having similar folds and percentage of helices and sheets (De Pereda et al. 1996). Multiple sequence alignment of the two proteins and proteolysis studies provided partial structural working models for tubulin and FtsZ structural regions at the GTP-binding site (De Pereda et al. 1996).

Studying the archaeal FtsZ bridged the gap between the prokaryotic and eukaryotic cytoskeleton, showing that FtsZ may have evolved to tubulin. In a study involving the isolation of a FtsZ homolog from an archaeal species Halobacterium salinarum, the FtsZ homolog was seen to be more related to tubulin of eukaryotes than to FtsZ of bacteria (Keeling \& Doolittle 1995, Margolin et al. 1996). FtsZ was thus proposed to be the prokaryotic cytoskeletal protein homolog of tubulin (Erickson 1995). The low sequence identity may suggest a convergent evolution for FtsZ and tubulin, but the similarity in their threedimensional structures strongly suggests a prokaryotic origin for the eukaryotic cytoskeleton (van den Ent 2001).

\section{Confirming the homology of FtsZ and tubulin through $\mathrm{X}$-ray crystal structures}

Microtubules are polymers of tubulin heterodimers. They are composed of two classes of tubulin- $\alpha$ and $\beta$ (Bryan \& Wilson 1971, Amos \& Klug 1974). Many additional classes of tubulin have been identified to date. $\gamma$ tubulin is involved in the nucleation of the microtubules and plays a role in regulation at the minus end (Joshi 1994, Oakley 1995). Other types of tubulin $\delta, \varepsilon$ and $\zeta$ have been identified but little is known about their structure and function (Findeisen et al. 2014).

Researchers had been trying to obtain the crystal structure of tubulin for at least two decades before it was finally resolved at a resolution of $3.7 \AA$ as an $\alpha \beta$ tubulin dimer using electron crystallography of zinc-induced tubulin sheets (Erickson 1998, Nogales et al. 1998b). As shown in Fig. 1A, both $\alpha$ and $\beta$ tubulin showed identical structures with a core of $\beta$ sheets surrounded by $\alpha$-helices. The structure is divided into three domains: N-terminal domain bearing the GTP-binding region, an intermediate domain, which has the taxol-binding site and the C-terminal domain postulated to be the binding region of motor proteins (Nogales et al. 1998b). The C-terminal domain was suggested to be involved in the binding of MAPs and functioned as a regulatory region during self-assembly (Serrano et al. 1984).

Soon after, FtsZ structure also came into light. In prokaryotic systems, the problems of genetic heterogeneity and post-translational modifications were absent making the crystallization process relatively easier. FtsZ was crystallized from Methanococcus jannaschii at a resolution of $2.8 \AA$ (Löwe \& Amos 1998). The crystal structures of the two proteins depict the similarity of the folds and domains in the two proteins and give insights to their assembly orientation. FtsZ upon folding gives
A

$\alpha$ tubulin

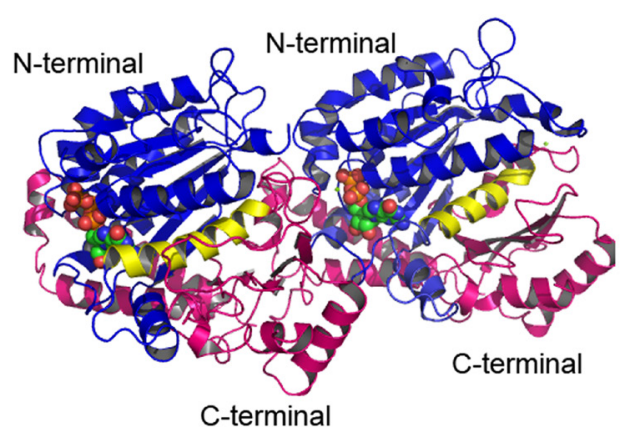

B

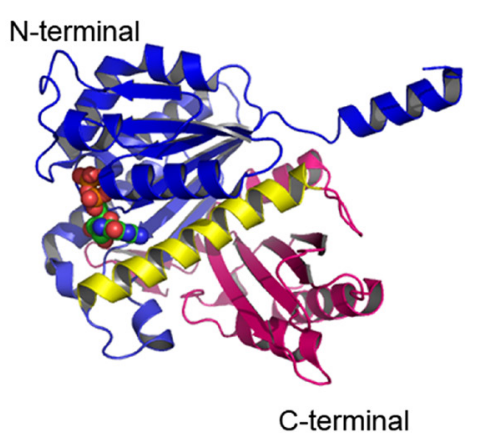

Figure 1

Tubulin and FtsZ show structural similarity. (A) Tubulin dimer with alpha and beta tubulin is shown as cartoon model. GTP and GDP nucleotides are bound to alpha and beta tubulin, respectively. They are shown as rainbow colored ball and stick models. (B) FtsZ is shown as a monomer with GDP bound to the $\mathrm{N}$-terminal. $\mathrm{N}$-terminals (blue) and C-terminals (pink) are separated by $\mathrm{H} 7$ helices (yellow). $\mathrm{N}$-terminal regions show the typical nucleotide-binding motif with parallel beta sheets connected by alpha helices known as the Rossmann fold. From these structures, the differences in C-terminal region between the two proteins are evident. The figures were rendered using PyMOL. PDB ID for tubulin: 1SAO. PDB ID for FtsZ: 1FSZ. http://erc.endocrinology-journals.org DOI: $10.1530 /$ ERC-17-0118
(C) 2017 Society for Endocrinology Printed in Great Britain 
two independent domains (Fig. 1B). A linker domain (H7 helix) connects the two domains. The N-terminal region shows the typical nucleotide-binding motif with parallel beta sheets connected by alpha helices, known as the Rossmann fold, also found in tubulin. This region was also shown to be important for the localization and assembly of FtsZ (Ma et al. 1996). The C-terminal domain contains a small, highly conserved (across prokaryotes) terminal region whose function was initially unknown as it was dispensable for the polymerization (Ma et al. 1996, Yu \& Margolin 1997). This C-terminal region is now found to be essential for the interactions with other membrane proteins like FtsA and ZipA (Ma \& Margolin 1999). A flexible linker region present at the C-terminal acts as a membrane tether for the cytokinetic ring formation (Buske \& Levin 2013). The active site is formed when the T7 loop in the C-terminal domain is in synergy with GTPase domain in the N-terminal of the next subunit. This enables the association dependant activation of the GTPase activity. Hydrolysis of GTP occurs by the hydrogen bonding of aspartate side chains in the T7 loop with water molecules, promoting the nucleophilic attack on the $\gamma$-phosphate. The N-terminal residue, glutamine (Gln75 in Methanococcus jannaschii FtsZ) helps in the polarization of the $\gamma$-phosphate in coordination with magnesium ion, water molecules and $\alpha, \beta$-phosphates (Löwe \& Amos 1998, Nogales et al. 1998a).

Comparing the structures of FtsZ and tubulin (Fig. 1), it is evident that $\mathrm{N}$-terminal domains of the two structures are, expectedly, similar. Even though the sequence similarity is completely absent in the C-terminal domains of FtsZ and tubulin, their three-dimensional structures are similar with some differences, as seen in Fig. 1. FtsZ has predominant $\beta$ sheet terminus while tubulin ends with $\alpha$ helices, which suggests that the C-terminal regions in tubulin arose due to functional demands of binding to motor proteins such as kinesin (Erickson 1998). Based on the orientation of tubulin dimers, the orientation of FtsZ subunits during assembly could be predicted.

\section{FtsZ and tubulin comprise a distinct family of GTPases}

The structures of FtsZ and tubulin show similarity to other G-proteins even though they do not contain the signature GTP-binding sequence present in other G-proteins (Erickson 1998). They have their own unique GTP-binding sequence, which supported the hypothesis that they shared a common ancestry (Erickson 1998).
Studying the active site residues of the two structures, it was suggested that GTP binding and hydrolysis involved the association of two subunits (Wang \& Lutkenhaus 1993, Erickson 1998, Mukherjee \& Lutkenhaus 1998). This also led to the proposal that tubulin, perhaps FtsZ too, was its own GAP (GTPase-activating protein) (Wang \& Lutkenhaus 1993, Erickson 1995, 1998). Binding studies and kinetics revealed that one mole of tubulin dimer binds two moles of the guanine nucleotide (Adelman et al. 1968). GTP bound to $\beta$ tubulin is hydrolyzed to GDP, which remains in the polymer till it is exchanged with GTP following depolymerization. This triggers another round of polymerization. The $\alpha$-tubulin does not exchange its bound GTP and this GTP is not hydrolyzed (David-Pfeuty et al. 1977, Spiegelman et al. 1977, Purich \& MacNeal 1978, Desai \& Mitchison 1997). However, one mole of FtsZ binds to one mole of GTP (Lu et al. 1998).

\section{Structures of FtsZ and tubulin polymers}

The surface lattice of microtubules is composed of 13 filaments in a 3-start helix (Ledbetter \& Porter 1964, Tilney et al. 1973). A 3-start helix is described by starting 3 parallel helices of monomers, one above the other, to cover the entire surface of the microtubule lattice (Desai \& Mitchison 1997). In a microtubule, one helical turn with one line of monomers will end 3 monomers above it (Desai \& Mitchison 1997). A model was constructed with alternating $\alpha$ and $\beta$ subunits to form a heterodimer of $8 \mathrm{~nm}$, which polymerized to give a longitudinal filament (Erickson 1974b). This arrangement makes the microtubules polar structures, with a plus end and a minus end. These linear protofilaments laterally interact with each other to give $25 \mathrm{~nm}$ wide hollow cylindrical polymers (Desai \& Mitchison 1997). To examine whether $\beta$ tubulin was present at the plus ends of microtubules labeling studies using GTP were done. Labeled GTP binds specifically to the plus ends showing that, at the plus end, an exchangeable GTP-binding site is available (Mitchison 1993). Another study used the motor protein kinesin, which binds to $\beta$ tubulin, as the label and showed that it binds to the plus end (Hirose et al. 1995). Antibodies against $\alpha$ tubulin were seen to bind to the minus end (Erickson \& Stoffler 1996, Fan et al. 1996). This gave the orientation of the dimer in the polymer with $\alpha$ at the minus end and $\beta$ at the plus end.

Both FtsZ and $\alpha \beta$ tubulin were shown to assemble into straight filaments, which then form the protofilaments (Bramhill \& Thompson 1994, Desai \& Mitchison 1997).
(C) 2017 Society for Endocrinology Printed in Great Britain
Published by Bioscientifica Ltd 
The alternate conformation, which was observed in the tubulin family, was that of rings or spirals, where the subunits are all in curved conformation (Erickson \& Stoffler 1996). Rings of tubulin were usually captured before the assembly and after the disassembly of microtubules (Borisy \& Olmsted 1972). These were seen to be continuous with the protofilaments of the microtubule wall (Erickson \& Stoffler 1996). This gives a typical fountain-like appearance to the microtubule ends, due to the curling of the protofilaments to form rings away from the microtubule walls (Warner \& Satir 1973, Erickson 1974a, Kirschner et al. 1974, Mandelkow et al. 1991, Erickson \& Stoffler 1996).

Like tubulin, rings formed by FtsZ in vitro are extensions of the protofilaments. There is a significant size difference between the tubulin rings and FtsZ rings. This is postulated to be due to the curved conformation occurring in all subunits in FtsZ, while in tubulin rings only $\beta$ subunits were curved (Erickson \& Stoffler 1996). In this regard, it was also proposed that the $\gamma$ tubulin rings, which have a similar diameter to that of FtsZ rings were curved protofilaments (Erickson \& Stoffler 1996). The structural evidence obtained from these studies pointed out that ring polymers are homologous across tubulin family (Erickson \& Stoffler 1996). The functions of these rings were expected to be found in disassembly, in force generation due to shifting from one conformation to the other, and in the nucleation of the assembly when it comes to $\gamma$ tubulin rings (Borisy \& Olmsted 1972, Erickson 1974a, Kirschner et al. 1974, Erickson \& Stoffler 1996).

\section{Alternating conformations of tubulin and FtsZ}

Tubulin, when bound to GTP favors the straight conformation while GDP-bound tubulin units adapt the curved conformation. The switch between the two conformations was postulated to be the driving force for assembly and disassembly (Melki etal. 1989, Erickson 1997). The force generated during the disassembly of microtubules could explain the mechanism for chromosome motion (Grishchuk et al. 2005, McIntosh et al. 2010). During polymerization, curved protofilaments change to the more favored straight conformation, and this transition is promoted as the monomers assemble. The transition from curved to straight state could be possible due to GTP binding (Nawrotek et al. 2011). However, experiments showed that unpolymerized tubulin in solution was in the curved conformation irrespective of whether it was bound to GTP or GDP (Buey et al. 2006, Rice et al. 2008, Brouhard \& Rice 2014). Thus, the transition of GTP-tubulin to straight conformation would take place as the subunits got incorporated into the microtubule (Kueh \& Mitchison 2009). Depolymerases are proteins that control the length of microtubules by accelerating growth and shrinkage. Depolymerases identified in the recent years affect the conformations of tubulin at the microtubule ends (Howard \& Hyman 2007, Brouhard \& Rice 2014). Some microtubule-associated proteins were also found to be conformation selective in binding to tubulin monomers for promoting assembly (Ayaz et al. 2012, 2014, Brouhard \& Rice 2014).

In a similar manner, FtsZ was seen to switch between the straight and the curved conformation, and it was proposed that this transition generates the necessary bending force to constrict the membrane (Erickson et al. 1996). Genetically modified FtsZ which could directly bind to the membrane, when introduced into liposomes in vitro, caused the membrane to constrict (Osawa et al. 2008, McIntosh et al. 2010). Further study in liposomes added evidence to the hypothesis that the membrane constriction was caused due to the force generated as a result of the change in the conformation of FtsZ filaments (Osawa et al. 2009). In addition, the C-terminal membrane tether of FtsZ is oriented toward the outside of the curved protofilament, which was opposite to what was observed in tubulin (Housman et al. 2016). This gave an insight into the evolutionary relationship between FtsZ and tubulin. Tubulin's precursor would have had similar features of that of FtsZ. As the evolution to tubulin took place, the straight conformation involved in forming the protofilaments was retained, but the inner bending or curvature was lost and replaced by the outer bending (Housman et al. 2016). This outer bending seems to be favorable due to its advantages during chromosome separation (Housman et al. 2016). A mechanical analogy of FtsZ to tubulin was established. Both proteins associated with larger cellular structures kinetochore for microtubules and cell membrane for FtsZ - alter their conformations with respect to the environment of the cell. The ability of these polymers to locally interact and undergo structural changes at the cellular level has been called the 'hallmark of cytoskeletal polymers' (McIntosh et al. 2010). The tubulin bending forces and their coupling to motile functions in the cell are still unexplored concepts and FtsZ, given its similarity to tubulin with respect to its mechanics, provides a platform for this study. 


\section{Dynamics of assembly}

GTP hydrolysis is tightly coupled to the assembly of microtubules while studies in vitro have demonstrated that the GTPase activity is not necessary for the assembly of FtsZ (Stewart et al. 1990, Mukherjee \& Lutkenhaus 1998). Yet, the dynamics of FtsZ filaments like the tubulin polymers is considered to be regulated by GTP hydrolysis (Desai \& Mitchison 1997, Mukherjee \& Lutkenhaus 1998). One of the first concepts of microtubule dynamics was that of treadmilling - so called because of the continuous association of tubulin dimers at one end of a microtubule and the dissociation of tubulin dimers from the other end of the microtubule occurring at the steady state of assembly (Margolis \& Wilson 1978). Dynamic instability was then introduced to describe the existence of a microtubule in prolonged states of polymerization and depolymerization without actually reaching the steady-state length (Mitchison \& Kirschner 1984, Desai \& Mitchison 1997). In an individual microtubule, both the ends exist in either of the two phases, the growing phase and the shortening phase. Using DIC microscopy, it was shown that microtubules alternate between an elongation phase and a rapid shortening phase (Walker et al. 1988). There is a continuous switch between the two phases in a stochastic manner. A study of the seeded assembly of pure tubulin using high-resolution microscopy, established elongation and shortening as two independent mechanisms (Housman et al. 2016). The active end (so called due to the rate of inter-conversion being more than the other end) shows more fluctuations in length and grows faster and shortens slower than the inactive end (Horio \& Hotani 1986, Walker et al. 1988). It was suggested that the biological function of dynamic instability could be the recycling of microtubules that have missed their targets (Erickson \& O'Brien 1992). Catastrophe is the switching of states from an elongation to a shortening state, while rescue represents the switching from a shortening to an elongation state (Walker et al. 1988). Although the polymerization reaction depends on tubulin concentration, depolymerization seems to occur independently of it (Desai \& Mitchison 1997, Housman et al. 2016). The interplay between catastrophe and rescue, the transition frequencies, kinetics of microtubule assembly and the influence of tubulin concentration pose as a complex concept and is poorly understood (Panda et al. 2002, Akhmanova \& Steinmetz 2015).

An important, now widely accepted theory of microtubule dynamics is that the growing microtubule filaments are stabilized by a 'GTP cap' that prevents catastrophe (Carlier \& Pantaloni 1981, Hill \& Carlier 1983, Mitchison \& Kirschner 1984, Melki et al. 1989, Panda et al. 2002). Loss of the GTP cap will expose the GDP-tubulin lattice leading to a catastrophe. 3D mechanochemical studies showed that the GTP-bound subunits interact strongly with each other while the GDP-bound subunits interact weakly. When the GTP cap is removed, the GDP-bound subunits will thus disassemble (Melki et al. 1989).

The growing microtubules have ends with relatively straight open sheets and the shrinking microtubules have ends with frayed, outward curling protofilaments (Mandelkow et al. 1991, Chrétien et al. 1995). The structural transitions at the polymer ends representing the structural plasticity of microtubules provide an alternative theory of microtubule dynamics beyond the GTP cap model (Kueh \& Mitchison 2009). By exchange of nucleotides, GTP for GDP, the conformation of tubulin subunits undergoes a loss in its curvature, which enables their association to protofilaments (Nogales \& Wang 2006). The GTP in the E-site is an allosteric effector, which drives the tubulin subunits to be in the straight conformation and forms a stable GTP cap at the microtubule ends (Melki et al. 1989). Hydrolysis of this GTP begins along with the assembly forming protofilaments with GDP-bound tubulin. As the GTP-tubulin subunits add to the growing end of microtubules, they straighten to give sheets. These sheets close to form the cylindrical tubes (Chrétien et al. 1995). The hydrolysis of GTP at the 'caps' will expose the GDP-tubulin subunits that tend to bend outwards, releasing the free energy stored during GTP hydrolysis before finally disassembling (Kueh \& Mitchison 2009). The process has been represented as a model in Fig. 2.

Catastrophe was said to be linked to the 'aging' of the microtubule tips (Coombes et al. 2013). As the microtubule grows, the tips become tapered with time, and this change is independent of the hydrolysis of GTP. Proteins that modify the microtubule tip structures might promote the catastrophe (Coombes et al. 2013).

Comparing to the plus end of microtubules that binds GTP, the GTP-binding surface of the FtsZ protofilaments has been named as the plus end (Scheffers \& Driessen 2001). Evidently, the variation in dynamics of FtsZ from microtubules arises from the fact that in FtsZ polymers, all subunits can exchange the nucleotide and that free FtsZ exists as a monomer rather than a heterodimer (Mukherjee et al. 1993, Sossong et al. 1999).

Published by Bioscientifica Ltc.
(C) 2017 Society for Endocrinology Printed in Great Britain 


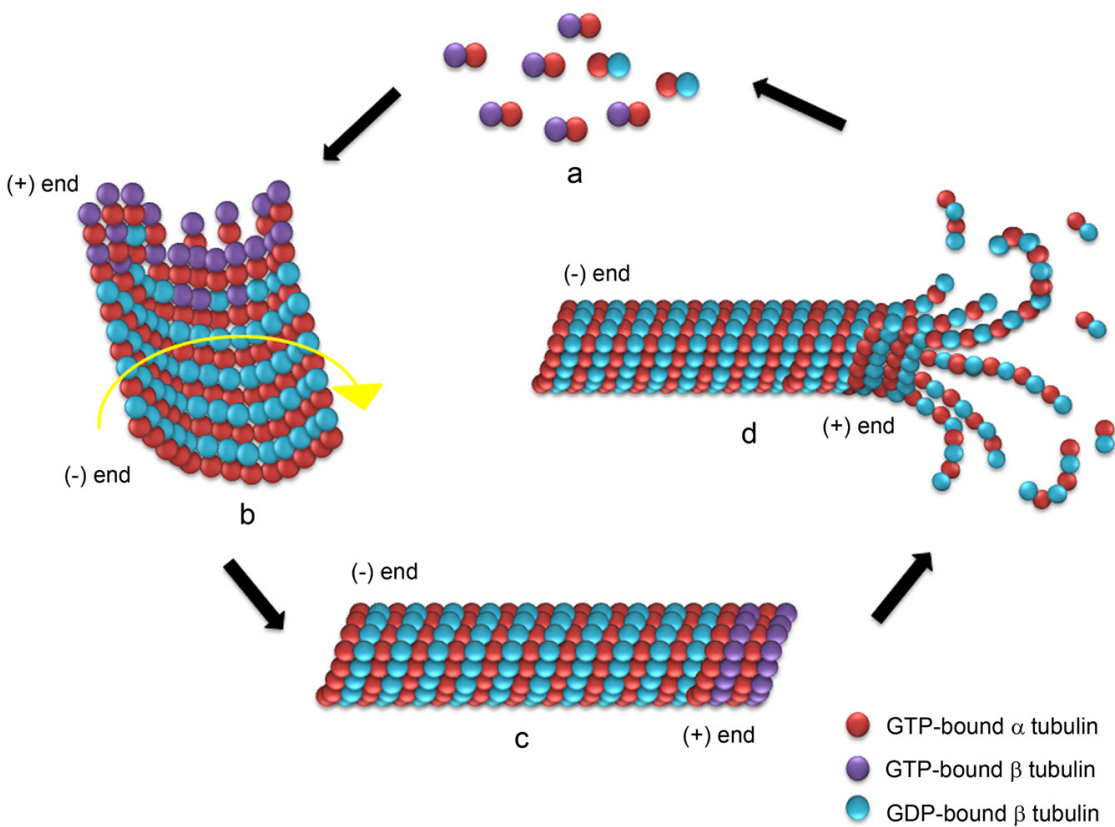

Figure 2

A model for microtubule assembly and disassembly is shown. (A) Free tubulin dimer bound to either GTP or GDP. (B) Tubulin dimers polymerize to form sheets of 13 protofilaments. (C) The sheets close to form a cylindrical tube. (D) Hydrolysis of GTP at the ends results in loss of GTP cap, exposing the GDP-tubulin lattice. GDP-tubulin units interact less strongly with each other, curling away from the tube and finally disassemble.
No evidence of FtsZ exhibiting dynamic instability has been found (Romberg \& Levin 2003). However, a recent study indicated that the reorganization of FtsZ polymers could be due to treadmilling (Loose \& Mitchison 2014). This study showed that FtsZ filaments in the presence of FtsA polymerized at one end and showed depolymerization at a faster rate at the opposite end emphasizing that large-scale dynamics of FtsZ is influenced by FtsA (Loose \& Mitchison 2014). The filaments of FtsZ and FtsA are involved in positioning enzymes required for septal peptidoglycan (PG) synthesis for cell division process. To understand septal PG synthesis, the dynamic movements of FtsA and FtsZ filaments with respect to the enzymes recruited to the division site were examined using pulse-labeling and 3D illumination microscopy (Bisson-Filho et al. 2017). The septum was found to be constructed discontinuously around the division plane. The treadmilling of FtsZ and FtsA filaments around the division plane in a circular fashion led to the relative motions of the enzymes required for PG synthesis, thereby controlling the rate of PG synthesis and cell division (Bisson-Filho et al. 2017).

While tubulin always forms multi-stranded protofilaments, FtsZ protofilaments can exist in the singlestranded state (Romberg \& Levin 2003). Like proposed for GDP-tubulin subunit interaction (Melki et al. 1989), FtsZ subunits bound to GDP interact less strongly with each other (Bramhill \& Thompson 1994, Mukherjee \& Lutkenhaus 1998, Sossong et al. 1999, Rivas et al. 2000, Romberg \& Levin 2003). In tubulin association, GTP hydrolysis is closely coupled to microtubule elongation, which is prevalent at the initial stages of assembly also (Vandecandelaere et al. 1999, Caplow \& Fee 2003). Therefore, most of the polymer consists of the GDP-tubulin. The crystal structure of the tubulin protofilaments explained this view by showing that the occluded region of GTP binding would not allow the nucleotide to be released even after it is hydrolyzed (Oliva et al. 2004, Romberg \& Mitchison 2004). This also was in conflict with the idea that the stabilization of growing microtubules was due to an extended GTP cap (Vandecandelaere et al. 1999, Caplow \& Fee 2003). During FtsZ polymerization, however, the rate-limiting step is the nucleotide hydrolysis and not nucleotide exchange. The filament structure of FtsZ has exposed GTP sites, which allow for easy exchange of nucleotides (Mingorance et al. 2001, Oliva et al. 2004). Polymerization studies that measured the content of nucleotides in FtsZ protofilaments using filter-binding assays concluded that the FtsZ polymer is mostly GTP bound (Mingorance et al. 2001, Huecas \& Andreu 2003).

Residues that establish the longitudinal contacts in microtubule filaments are conserved in FtsZ, while those which are involved in lateral contacts are not present in FtsZ (Nogales et al. 1998a). Lateral contacts cause bundling induced by magnesium, calcium and ruthedium red, in vitro (Yu \& Margolin 1997, Rivas et al. 2000, Santra et al. 2004, Erickson et al. 2010). However, the physiological relevance of these in vitro studies on lateral contacts is still poorly understood.

Recent in vivo cryoelectron tomography studies done in Caulobacter crescentus revealed that the Z-ring is made

Published by Bioscientifica Ltd 
up of loosely arranged irregular patches of protofilaments, which gives it an overall discontinuous structure (Li et al. 2007, Holden et al. 2014). Following studies using highresolution fluorescence microscopy techniques revealed that such was the case in many other bacterial species (Strauss et al. 2012, Rowlett \& Margolin 2014, Jacq et al. 2015). It was also hypothesized that GTP-bound FtsZ assemble into straight protofilaments at many nucleation points at the mid-cell and attach themselves to the membrane (Lu et al. 2000). Unlike tubulin, GTP hydrolysis does not take place immediately. They establish lateral contacts to form a discontinuous Z-ring at the mid-cell region. GTP hydrolysis will induce a conformational change from straight to curved form of FtsZ subunits. This causes the overlapping filaments of FtsZ polymers to slide along each other and generate a contractile force that helps in membrane constriction (Lu et al. 2000, Lan et al. 2009, Szwedziak et al. 2014). However, recent studies have suggested that Z-ring remodeling for membrane constriction is due to polymerization dynamics and not because of previously proposed sliding mechanism (Li et al. 2007, Niu \& Yu 2008, Lan et al. 2009, Loose \& Mitchison 2014). The GDP-bound subunits are unstable and will finally result in depolymerization (Fig. 3).

However, it was shown that, even though the Z-ring displays a patchy network of FtsZ filaments, the finestructural organization varies among different bacterial species. This variation is attributed to the variation in the modes of cytokinesis and array of divisome proteins present, differing from species to species (Haeusser \& Margolin 2016). FtsZ does not only exist as a part of the cytokinetic Z-ring, but also forms highly dynamic helical cytoskeleton in the rest of the cell (Thanedar \& Margolin 2004) indicating a strong analogy with the cytoplasmic microtubules that organize into multiple structures inside the eukaryotic cells.

The cooperative model shows assembly that starts with one dimer, which favors the attachment of the next subunit, which further favors the attachment of another and so on. This model is also called the lateral cooperative assembly model, which involves the stabilization of a dimer by a third subunit at a different interface. There is a slow nucleation phase and a rapid growth phase. For multi-stranded polymers such as microtubules, this model of assembly seems to fit well while for single-stranded polymers such as FtsZ filaments, there was much debate over whether the assembly was isodesmic or cooperative. Isodesmic assembly of FtsZ was proposed based on characteristics such as the single-subunit thickness of the protofilaments and rapid polymerization of FtsZ without a clear nucleation phase (Romberg et al. 2001). However, more evidence for the cooperative model was collected over the years. It was shown that during assembly, pairs and bundles of protofilaments were formed, which indicated the presence of more than one kind of bond between the subunits (Mingorance et al. 2001, Huecas \& Andreu 2003, Oliva et al. 2003). The absence of hydrolysis below a certain concentration of the protein provided evidence for the cooperative behavior of FtsZ assembly and suggested that the assembly requires a critical concentration of FtsZ. An increase in concentration showed higher activity and greater extent of polymerization (Wang \& Lutkenhaus 1993, Oliva et al. 2003, Romberg \& Mitchison 2004). The kinetics of FtsZ assembly as monitored by fluorescence fit the cooperative mechanism well. The length of the polymers remained uniformly independent of the total protein concentration (Chen et al. 2005). Thus, the cooperative mode of assembly has been accepted as the model for FtsZ assembly.

It was also derived that the $\mathrm{N}$-domain of $\mathrm{FtsZ}$ is analogous to $\beta$-subunits of tubulin, which have the ability to form polymers-sheets, rings (Oxberry et al. 2001). A recent study on the $\mathrm{N}$-terminal and $\mathrm{C}$-terminal regions of FtsZ showed that truncated N-domains polymerized to form filaments while truncated C-domains did not show polymerization. This supported the hypothesis of the directional assembly of FtsZ (Jindal \& Panda 2013).

Microtubule and FtsZ dynamics have constantly influenced each other in the study of assembly dynamics

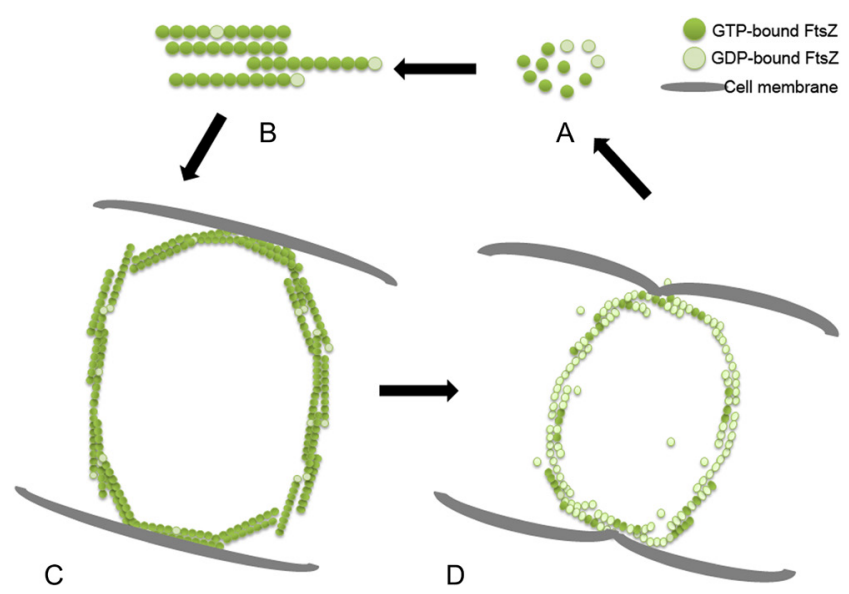

Figure 3

A model for Z-ring assembly and disassembly. (A) Free FtsZ (monomer) exists predominantly as GTP-bound state. (B) GTP-FtsZ associates to form longitudinal filaments. (C) Protofilaments laterally contact to form a discontinuous Z-ring at the mid-cell region. (D) GTP hydrolysis leads to change in conformation as GDP-FtsZ is in curved state, which helps in membrane constriction. Finally Z-ring disassembles completely and cytokinesis occurs.

Published by Bioscientifica Ltc. 
of cytoskeletal polymers. Even though the overall mechanism of tubulin dynamics has been understood, the understanding of the dynamics within the GTP cap is minimal. Understanding FtsZ dynamics is a key to unveiling ideas about microtubule core dynamics.

\section{Associating proteins of the cytoskeleton}

The dynamics of microtubules and FtsZ play important roles during cell division. Microtubule organization and dynamics are regulated by several proteins that alter the behavior of microtubules known as microtubuleassociated proteins (MAPs). MAP2, MAP4 and tau have similar repetitive microtubule-binding regions, which interact with the C-terminal region of tubulin subunits and stabilize the microtubules (Maccioni \& Cambiazo 1995). Several other proteins such as stathmin are known to destabilize microtubules (Belletti \& Baldassarre 2011, Biaoxue et al. 2016). MAPs energized the search for similar associating array of proteins that interact with FtsZ and regulate its assembly. Similar to tubulin, the C-terminal domain region of FtsZ bears a C-terminal linker that participates in interaction with FtsZ-associated proteins (Vaughan et al. 2004, Singh et al. 2007, 2008a, Kuchibhatla et al. 2011, Buske \& Levin 2013, Ortiz et al. 2016). Recently, many proteins of the divisome of bacteria involved in cytokinesis have been identified and characterized (Massidda et al. 2013). Initiation of the assembly of the Z-ring is preceded by the spatial regulation of FtsZ at the mid-cell by negative spatial regulators such as Min proteins, which restrict the Z-ring assembly to mid-cell and inhibit their assembly at the cell poles (Raskin \& de Boer 1999); positive spatial regulators like MapZ in S. pneumoniae lead to the localization of FtsZ at the mid-cell directly and stimulate assembly (Fleurie et al. 2014). FtsZ is now tethered to the membrane forming the Z-ring. Membrane-associated proteins such as ZipA and FtsA in E. coli mediate the attachment of the Z-ring to the cell envelope (Haeusser \& Margolin 2016). ZipA is proposed to be the ancient prototype of MAP2/Tau family members (RayChaudhuri 1999, Dehmelt \& Halpain 2005). It prevents the ClpXP-directed degradation of Z-ring (Pazos et al. 2013). SepF, a protein that enhances FtsZ assembly (Singh et al. 2008a), is thought to complement FtsA in early stages of formation of the Z-ring (Ishikawa et al. 2006). MciZ, an inhibitor of Z-ring formation in bacteria, binds to the minus end of the FtsZ filaments and produces shorter filaments, which are unable to form the Z-ring (Bisson-Filho et al. 2015).

\section{Bridges between FtsZ and tubulin}

FtsZ/tubulin superfamily of proteins consists of major cytoskeletal proteins found in all three domains of life archaea, bacteria and eukaryotes. Some of these proteins are paralogs and orthologs of FtsZ found in eukaryotes and of tubulin found in archaea and bacteria. These proteins open new doors to study the cytoskeletal evolution from prokaryotes to eukaryotes. Gain and loss of functions as the proteins evolved represent new adaptations to incorporate the complexities of eukaryotic living. It is believed that during evolution, archaea diverged from its bacterial ancestors and further archaea and eukaryota diverged from each other. So it was likely to find a cytoskeletal protein similar to its prokaryotic ancestor, yet showing new properties similar to the eukaryotic successor. CetZ is a family of proteins present in archaea, which bears resemblance to both prokaryotic FtsZ and eukaryotic tubulin. Sequence alignments of CetZ with tubulins and FtsZ show that the active site residues are identical for tubulin and CetZ, while other regions of CetZ show greater similarity to FtsZ (Vaughan et al. 2004, Yutin \& Koonin 2012, Duggin et al. 2015). FtsZ and CetZ/ tubulin diverged during the evolution and further, and CetZ and tubulin diverged as cell architecture evolved (Yutin \& Koonin 2012). This protein is found to co-exist with FtsZ indicating dynamic structural and cytoskeletal behavior of the protein inside the cell (Duggin et al. 2015).

Apart from archaea, proteins similar to tubulin are found in other species of bacteria as well. FtsZ is one of the most conserved proteins present in almost all bacteria, with the exception of a few families of Verrucomicrobia and genus Chlamydia (Mahendran et al. 2011). BtubA and BtubB were discovered in a bacterial species of Verrucomicrobia phylum, Prosthecobacter dejongeii, which lacked FtsZ. These proteins bear more resemblance to eukaryotic tubulin than to FtsZ, in terms of their sequence (Jenkins et al. 2002). Structural analysis suggested that the presence of these genes in bacteria may be due to the horizontal gene transfer from a eukaryotic organism (Schlieper et al. 2005). In vitro assembly studies revealed that BtubA did not polymerize on its own. However, BtubB assembled to form rings whose diameter was very close to that of microtubule single rings (Sontag et al. 2005). BtubA and BtubB together formed bundles of protofilaments similar to the calcium-induced bundles of FtsZ protofilaments, unlike the microtubule wall with regular lateral interactions ( $\mathrm{Lu}$ et al. 2000, Sontag et al. 2005). These proteins provide a new platform for mutation analysis studies of tubulin in vivo

Published by Bioscientifica Ltc. 
(Sontag et al. 2005). In vivo electron microscopy studies revealed that BtubA/B form microtubule-like lattice forming 5-filament cylinders rather than the 13-filament of typical eukaryotic microtubules. It was proposed that these should be called 'bacterial microtubules' (Pilhofer et al. 2011).

Cytoskeletal proteins across prokaryotes and eukaryotes are involved not only in cell division, but also in the division of other structures and organelles inside the cell. One such protein of the FtsZ/tubulin superfamily is TubZ, involved in the division of low copy number plasmids (Larsen et al. 2007). TubZ, isolated from Bacillus thurigiensis, was considered to be homologous to FtsZ and tubulin based on the similarity of its X-ray crystal structure to that of tubulin and FtsZ ( $\mathrm{Ni}$ et al. 2010). Characteristics of TubZ such as high critical concentration, rapid GTP hydrolysis rate and filaments made of subunits mostly bound to GDP are similar to those of tubulin (Anand et al. 2008, Chen \& Erickson 2008, Akhtar et al. 2009, Aylett et al. 2010). A GTP cap model for this protein assembly was suggested based on these observations (Chen \& Erickson 2008). Polymerization studies revealed that TubZ undergoes treadmilling and bundling, unlike FtsZ (Larsen et al. 2007, Anand et al. 2008). Electron microscopic observations indicated that TubZ forms parallel double helical filaments in vitro and in vivo, which show rotational symmetry, unlike tubulin (Aylett et al. 2010). The unique dynamics may explain the function of TubZ to be of a partitioning protein for plasmid segregation (Aylett et al. 2010). The unique sequences may be responsible for the ability of these proteins to twist and writhe, showing the adaptation of FtsZ/tubulin family cytoskeletal protein for cytomotive functions such as plasmid segregation (Aylett et al. 2010).

\section{FtsZ from eukaryotic organelles}

Chloroplasts and mitochondria are derived from prokaryotic organisms called endosymbionts (Gray 1999, Cavalier-Smith 2000, McFadden 2001). FtsZ in chloroplasts and other non-synthetic plastids was derived from the cyanobacterial ancestor of these organelles (Vitha et al. 2001, TerBush et al. 2013). Unlike in bacteria, FtsZ found in plastids have two phylogenetically distinct families of FtsZ, which co-localize at the division site to form the Z-ring (Osteryoung et al. 1998). However, the biochemical properties and dynamic behaviour of the two are different (Osteryoung et al. 1998). The two FtsZs represent gene duplication during chloroplast evolution from cyanobacteria to algae and further, to higher plants (Osteryoung et al. 1998, Osteryoung \& McAndrew 2001, Miyagishima et al. 2004). Recent studies on Arabidopsis chloroplast FtsZ families-FtsZ1 and FtsZ2 showed that FtsZ1 could co-assemble with FtsZ2 to form heteropolymers in vitro, showing extensive bundling with lateral interactions (Olson et al. 2010). The functional significance of such assembly in vivo is still elusive. The study of chloroplast FtsZs will give more insight into chloroplast evolution and the gene duplication of FtsZ in eukaryotic forms (TerBush et al. 2013).

Mitochondrial FtsZ isolated from chromophytealgal species (Beech et al. 2000, Takahara et al. 2000) bears resemblance to $\alpha$-proteobacterial FtsZ (Beech et al. 2000). The division of mitochondria was also seen to be similar to that of plastid, involving two families of FtsZ proteins forming the ring at the division site (Takahara et al. 2001, Nishida et al. 2003). However, in higher eukaryotes, the gene encoding FtsZ is absent, indicating the loss of mitochondrial FtsZ during evolution (Miyagishima et al. 2004). Investigation of the mitochondrial division machinery of higher plants will thus provide insights into the evolutionary selection against FtsZ proteins and significance of the proteins that replaced FtsZ to carry out the function.

\section{Targeting tubulin and FtsZ}

FtsZ and tubulin form essential polymers for the growth and division of the prokaryotic and eukaryotic cells, respectively. Therefore, targeting FtsZ and tubulin presents an interesting strategy for antibacterial and anticancer therapy. Several compounds have been discovered over the years that target tubulin and disrupt microtubule dynamics. These agents stall mitosis and finally induce apoptosis of the cells. Clinical use of these compounds as anticancer drugs has been popular since the late 90s. In addition, many of the microtubule-targeting agents are presently in clinical trials for the treatment of various cancers such as pancreatic, breast and prostate cancer. Microtubule stabilizing agents promote microtubule assembly and prevent its depolymerization. Paclitaxel is one of the first microtubule-stabilizing agents identified (Schiff $e t$ al. 1979) and since then, many derivatives and analogs of it have been discovered (Singh et al. 2008b, Field et al. 2014). Vinblastine, combretastatin, estramustine and colchicine are among the popular microtubule destabilizing agents. Vinblastine, one of the most successful microtubuletargeting agents, has been in use for the treatment of cancer since 1960 (Field et al. 2014). Estramustine, a valuable drug used to treat hormone refractory prostate

Published by Bioscientifica Ltd. 
cancer, was shown to dampen the dynamic instability of individual microtubules by suppressing the rate of growth and shortening and increasing the time duration of the pause state of the microtubules (Panda et al. 1997, Mohan \& Panda 2008).

Combretastatin A4 phosphate (CA-4P), a member of the combretastatin family, inhibits tubulin polymerization and blocks cells at mitosis (Jordan \& Wilson 2004). The drug binds to tubulin at the colchicine-binding site. CA-4P is a disodium phosphate derivative of CA-4 drug and exhibits enhanced water solubility. It underwent phase I clinical trials for anticancer therapy (Stevenson et al. 2003, He et al. 2011). Neurotoxicity and cardiovascular toxicity effects of CA-4P present major limitations (Rustin et al. 2003). Several analogs of CA-4 have been synthesized to minimize these effects. This led to the identification of a new combretastatin-2-aminoimidazole analog having better efficacy than CA-4 (Fig. 4) (Chaudhary et al. 2016). The compound exerts much stronger effects on microtubules than CA-4.

Other than antitumor therapy, microtubuletargeting agents have also been studied as drug targets in neurodegenerative diseases. TP-287 has the ability to cross the blood-brain barrier, target tau protein and is currently under clinical trials for the treatment of brain cancer and Alzheimer's disease (Field et al. 2014).

Although microtubule-targeting agents have been investigated extensively, the studies on FtsZ inhibitors are limited. FtsZ being the master coordinator of cytokinesis, when inhibited, would lead to the prevention of Z-ring formation. The failure of septation and division would thereby lead to cell death. Being one of the most highly conserved proteins in bacteria, inhibitors of FtsZ can be used as broad-spectrum antibiotics to target a wide range of pathogens (Rothfield et al. 1999, Margolin 2000,
Kapoor \& Panda 2009, Singh et al. 2012, Ojima et al. 2014, Panda et al. 2016). The structural and functional homology of tubulin and FtsZ provides a platform to explore the possibility of studying agents that target tubulin as FtsZ inhibitors or at least as potential leads for them. The differences in some of the sequence regions and polymerization properties will allow the discovery of anti-FtsZ agents specific to prokaryotic cells, which have minimum effects on eukaryotic cells.

In an attempt to identify FtsZ-targeting agents based on anti-tubulin agents, Mycobacterium tuberculosis FtsZ was used to screen for taxane derivatives that showed anti-FtsZ activity. Some of them showed significant cytotoxicity against bacteria and were categorized as potential antituberculosis agents (Huang et al. 2006, Kumar et al. 2010). A taxane derivative, SB-RA-2001, was recently identified to have minimum host cytotoxicity and $\mathrm{MIC}_{99}$ value (Huang et al. 2006). The compound promotes the assembly of purified FtsZ and stabilizes FtsZ filaments and unlike paclitaxel, SB-RA-2001 did not promote and stabilize the assembly of tubulin (Singh et al. 2014). Without affecting karyokinesis, SB-RA-2001 seems to inhibit the localization of FtsZ to form the Z-ring (Fig. 5). It inhibited the proliferation of Bacillus subtilis and Mycobacterium smegmatis cells and induced filamentation in these cells. It is proposed that the mechanism of action of SB-RA-2001 on FtsZ is similar to that of paclitaxel on microtubules (Singh et al. 2014).

PC190723, a potent taxane-related compound was shown to have inhibitory effects on Bacillus subtilis, Staphylococcus species and a methicillin-resistant Staphylococcus aureus strain (Haydon et al. 2008). Clinical studies on mice infected with a lethal dose of staphylococcal infection were treated with PC190723. Mice treated with the drug showed $100 \%$ survival while
A
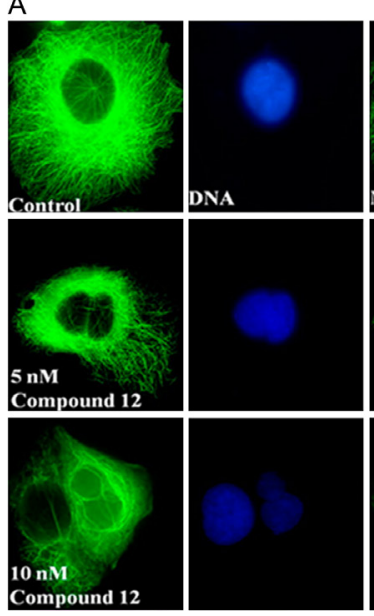

B

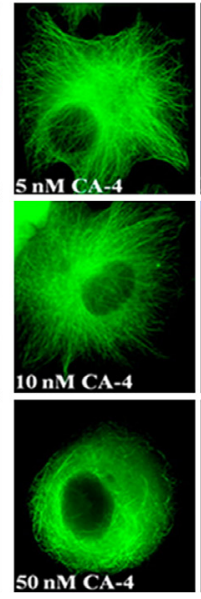

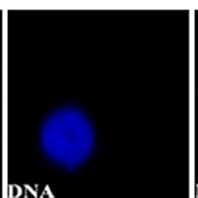

DNA

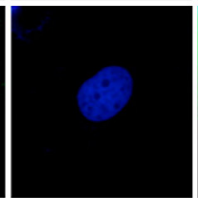

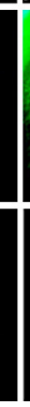

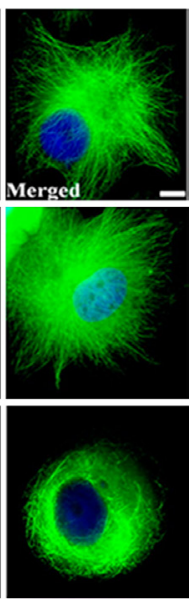

Figure 4

Effects of CA-4 and compound 12 on microtubules. Compound 12 (panel A) depolymerizes microtubules (green) more strongly than CA-4 (panel B). Reproduced with permission from Chaudhary V, Venghateri JB, Dhaked HPS, Bhoyar AS, Guchhait SK \& Panda D 2016 Novel combretastatin-2-aminoimidazole analogues as potent tubulin assembly inhibitors: exploration of unique pharmacophoric impact of bridging skeleton and aryl moiety. Journal of Medicinal Chemistry 59 3439-3451. Copyright 2016 American Chemical Society. 

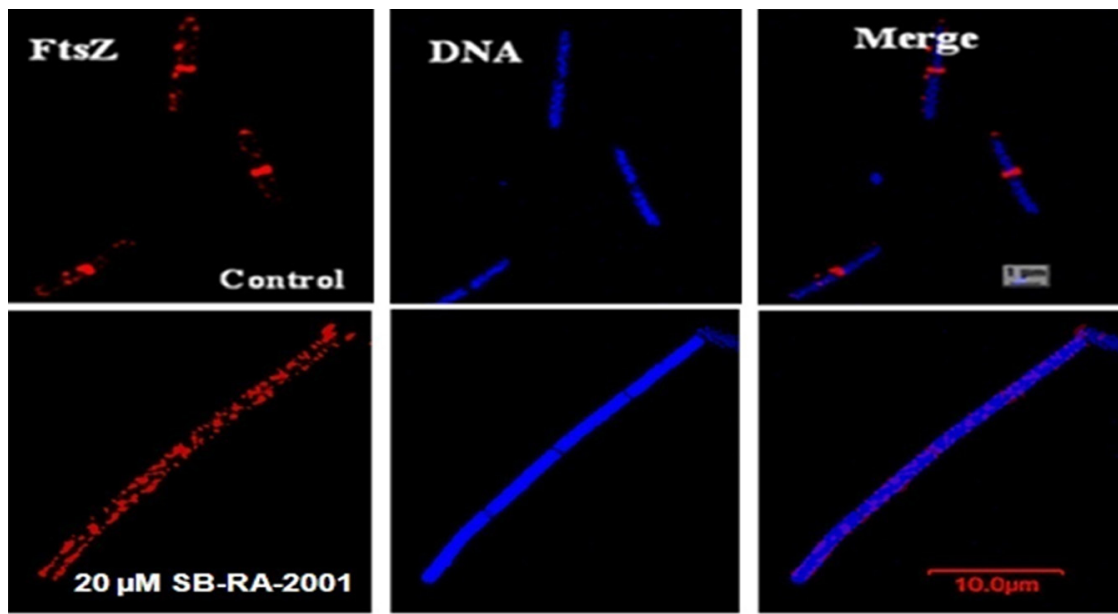

$20 \mu M$ SB-RA-2001
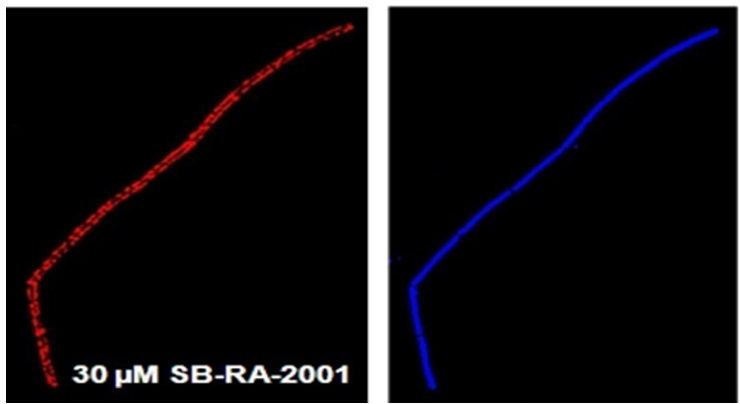

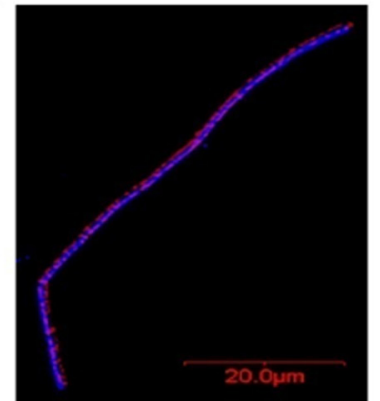

Figure 5

SB-RA-2001 perturbed the Z-ring formation without affecting nucleoid segregation. The immunostaining of Bacillus subtilis 168 cells showing the localization of FtsZ (red) and DNA (blue) in the absence and presence of compound. This compound adversely affects the localization of FtsZ at mid-site of cell. Reproduced with permission from Singh D, Bhattacharya A, Rai A, Dhaked HPS, Awasthi D, Ojima I \& Panda D 2014 SB-RA-2001 inhibits bacterial proliferation by targeting FtsZ assembly. Biochemistry 53 2979-2992; Copyright 2014 American Chemical Society. Figures available under the terms of the ACS AuthorChoice License. those which were not treated with the drug did not survive. The efficacy and selectivity of the drug showed its ability to be a potential candidate for anti-staphylococcal therapy (Haydon et al. 2008).

Benzimidazole derivatives, used in chemotherapy of cancer, fungal and neuroleptic diseases, have also been shown to target FtsZ by affecting the polymerization and GTPase activity. One of the benzimidazoles, BT-benzo-29, was found to inhibit the formation of Z-ring and to perturb the localization of FtsZ-interacting proteins in bacteria as seen in Fig. 6 (Ray et al. 2015). The localization of GFP-tagged proteins - FtsZ, FtsA, SepF and ZapA in Bacillus subtilis cells are disturbed in the presence of the drug (Ray et al. 2015). It had a minimal effect on the assembly of tubulin. Another compound, CXI-benzo-84, showed similar effects on tubulin by inhibiting the assembly and GTPase activity of tubulin in vitro (Rai et al. 2013).

OTBA (3-\{5-[4-oxo-2-thioxo-3-(3-trifluoromethylphenyl)-thiazolidin-5-ylidenemethyl]-furan-2-yl\}-benzoic acid) was identified among 81 compounds for targeting FtsZ (Beuria et al. 2009). OTBA was shown to inhibit the proliferation of bacterial cell more strongly than the mammalian cells. The compound promoted the assembly of FtsZ and enhanced the bundling of FtsZ polymers while it had no discernible effect on tubulin assembly. Similar to the action of FtsZ-associated stabilizing proteins such as SepF and ZipA, OTBA inhibited the dilution-induced disassembly of preformed FtsZ polymers indicating that OTBA stabilizes FtsZ polymers. Further, OTBA was found to reduce the GTPase activity of FtsZ (Beuria et al. 2009).

Curcumin, a dietary polyphenolic compound, is found to have both antibacterial and anti-microtubule properties (Rai et al. 2008, Banerjee et al. 2010). Recently, a potent carbocyclic curcumin analog (2d) was discovered, which inhibited Bacillus subtilis proliferation by targeting the assembly of FtsZ (Groundwater et al. 2017). 2d inhibited the assembly of FtsZ in vitro, whereas it had minimal effects on the assembly of tubulin. Interestingly, $2 \mathrm{~d}$ strongly enhanced the GTPase activity of FtsZ while it reduced the GTPase activity of tubulin. The differential effect of this compound on bacteria and mammalian cells makes the compound a selective, potential drug for treating bacterial infections (Groundwater et al. 2017).

\section{Comparison of the binding sites of the inhibitors of tubulin and FtsZ}

The structural similarity between FtsZ and tubulin does not necessarily imply that the active sites and the binding pockets formed by these proteins are similar. Differences arise from the extents of solvent accessibility of the nucleotide-binding pockets in these proteins. The

Published by Bioscientifica Ltd. 

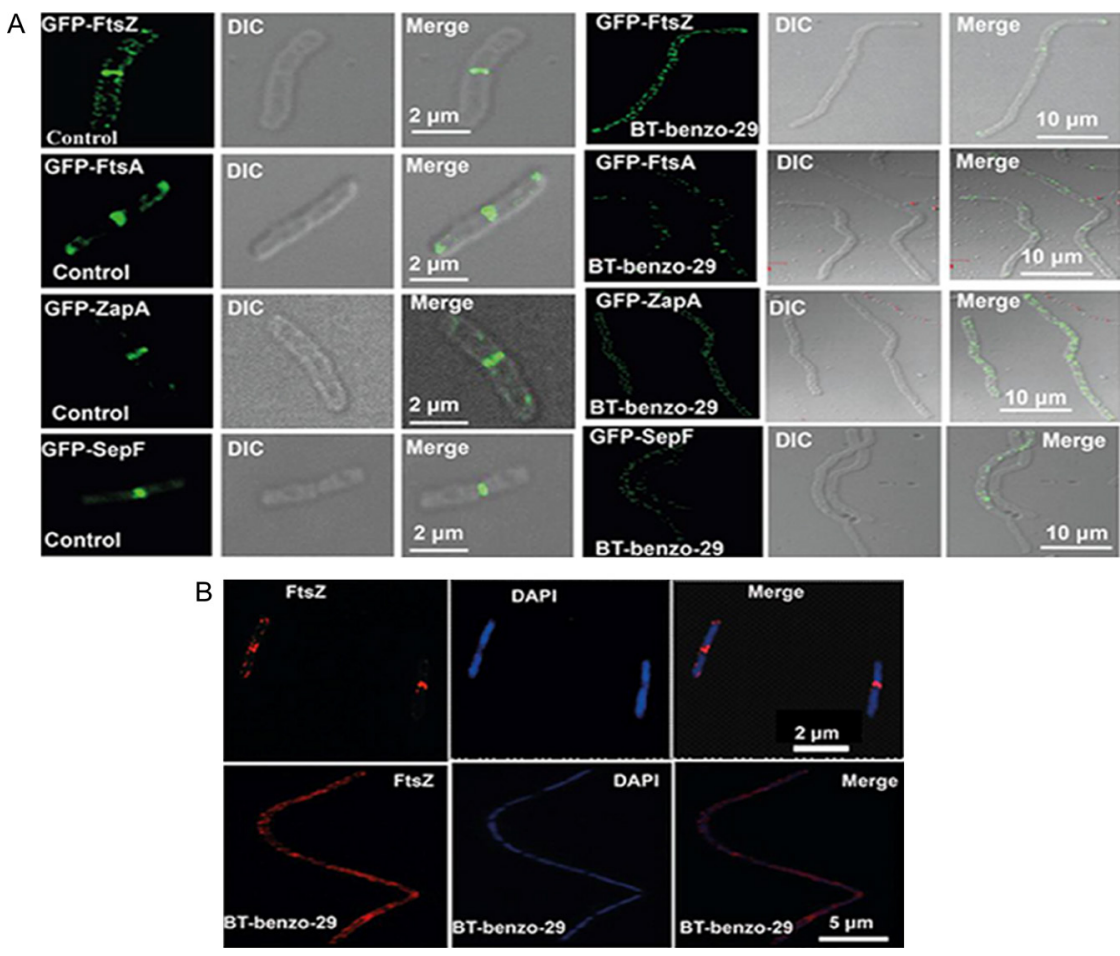

\section{Figure 6}

Effects of BT-benzo-29 on the localization of FtsZ and its associated proteins. (Panel A) The cell division proteins GFP-FtsZ, GFP-FtsA, GFP-ZapA and GFP-SepF localize at the center in the control cells. These proteins do not localize at mid-cell and diffuse throughout the length in the treated cells. Panel B shows the disrupting effect of BT-benzo-29 on the Z-ring without perturbation of the nuclear material. Reproduced with permission from Ray S, Jindal B, Kunal K, Surolia A \& Panda D 2015 BT-benzo-29 inhibits bacterial cell proliferation by perturbing FtsZ assembly. FEBS Journal 282 4015-4033. Copyright 2015 FEBS nucleotide is exchangeable in FtsZ protofilaments while it is not exchangeable in tubulin protofilaments, which have occluded binding pockets, making the active site of FtsZ more open and partially water-filled. The tubulin GTP-binding site is more hydrophobic than that of FtsZ (Oliva et al. 2004, Läppchen et al. 2008). Agents that target microtubules and FtsZ could interact with the proteins by binding to the nucleotide site or by binding to other regions of the structure.

Over the years, many small-molecule inhibitors of tubulin have been identified and are found to bind to one of the three well-characterized ligand sites - taxol, vinca and colchicine sites (Jordan \& Wilson 2004). Highresolution X-ray crystal structure revealed the residues participating in the binding of colchicine (Ravelli et al. 2004). The steric hindrance between the residues of $\alpha$ subunit and colchicine bound to $\beta$ subunit is responsible for the prevention of establishment of lateral contacts during the polymerization of tubulin, which explains the destabilizing effect of this compound (Ravelli et al. 2004). There is a switching of the T7 loop from its normal position (when unbound to ligand) to accommodate the ligand at this site (Dorleans et al. 2009). Many compounds bind at this interface and are called colchicine-binding site inhibitors (Wang et al. 2016). Vinblastine, also induces such a conformational change in microtubules, but at the inter-dimer interface (Gigant et al. 2005). While vinblastine binds to both $\alpha$ and $\beta$ subunits, taxol interacts with the $\beta$ subunit residues. The M-loop of the subunit is especially important in binding to the taxane ring (Löwe et al. 2001). The structural insights derived from these ligand-tubulin interactions can help us not only in identifying new drugs that target microtubules, but also to study the mechanisms of ordered assembly, disassembly, conformational switching along with the structural changes occurring with respect to these compounds and the role GTP plays in it.

Several compounds have been identified that target the GTP-binding site of FtsZ and thereby inhibit polymerization (Läppchen et al. 2008, Chan et al. 2013, Ruiz-Avila et al. 2013, Panda et al. 2016). A study using GTP analogs established several molecules to have potent anti-FtsZ activity, while some among them showed differential effects on tubulin activity (Läppchen et al. 2008). The difference in the nucleotidebinding sites, will allow the specific targeting of bacteria inside a mammalian host. These studies also establish the nature of interaction of GTP and the residues of the nucleotide-binding site of FtsZ. Another study used structure-based virtual screening to identify natural pyrimidine-substituted quinuclidines as FtsZ inhibitors (Chan et al. 2013). Using induced fit docking analysis, it was predicted that some of these compounds mimicked GTP and were able to establish key interactions within the triphosphate, sugar and nucleotide-binding regions of FtsZ (Chan et al. 2013). 
Many other compounds that interfere with FtsZ polymerization have also been identified, which bind to FtsZ at different sites other than the nucleotide-binding sites (Kapoor \& Panda 2009, Panda et al. 2016). It is highly useful in terms of specificity, to identify anti-FtsZ agents that target unique sites in the protein, and not the nucleotide-binding site, which is similar to that in mammalian tubulin.

Crystal structure of Staphylococcus aureus FtsZ bound to PC190723 showed that the compound is present at a narrow pocket deep within a cleft formed by the C-terminal half of the H7 helix, the T7 loop and the fourstranded C-terminal sheet (Tan et al. 2012). This binding site has been compared to the taxol-binding site of tubulin. The mechanism of action of these compounds on their respective proteins is also similar. This lead to reporting PC as a new class of FtsZ polymer-stabilizing agents (Andreu et al. 2010). Docking of SB-RA-2001 showed the compound to bind at the site of PC190723 binding, near the cleft at the C-terminal (Singh et al. 2014). The putative binding site for BT-benzo-29 was identified using site-directed mutagenesis and molecular docking studies (Ray et al. 2015). The compound binds to the C-terminal region of the protein involving hydrophobic residues leucine, glycine, proline and valine (Ray et al. 2015). STD NMR and docking studies suggested the binding site for cinnamaldehyde, an antibacterial agent that targets FtsZ, to be around the T7 loop (Domadia et al. 2007) similar to SulA, a known cell division inhibitor that interacts with FtsZ (Cordell et al. 2003). It was also suggested that the binding of the compound to this region induces a conformational change in the protein, which could interfere in its polymerization and GTPase activity (Domadia et al. 2007). CRAMP (16-33), an inhibitor of FtsZ assembly, is predicted to interact with the T7 loop of FtsZ (Ray et al. 2014).

Though several studies examined the binding of FtsZ inhibitors, their binding sites on FtsZ are not well characterized. It has been suggested that FtsZ has a smaller number of regions that the small molecules can bind to, while tubulin has many such regions, making it a relatively easier protein to target (Hurley et al. 2016). The putative binding sites of several FtsZ-targeting agents seem to be around the T7 loop, also present in host tubulin which raises questions about the specificity of such compounds. Compounds targeting the GTP-binding domain also raise similar queries. Identification of alternative target-binding sites would be useful in accelerated development of drugs against FtsZ.
Targeting FtsZ and tubulin follows the same principle and the studies done on the two have influenced each other in several ways. Be it with respect to the binding site interactions, mode of action and the development of derivatives of the compounds. However, agents targeting tubulin such as colchicine, paclitaxel, vinblastine and benomyl have no discernable effect on FtsZ assembly (Yu \& Margolin 1998, White et al. 2000, Beuria et al. 2005). Most of the FtsZ inhibitors currently under study such as PC197023, BT-benzo-29 and OTBA also show minimal effects on tubulin polymerization (Haydon et al. 2008, Beuria et al. 2009, Ray et al. 2015). The differential effect of these compounds raises the possibilities of finding inhibitors that specifically target FtsZ without harming the eukaryotic host.

\section{Conclusion}

Since tubulin and FtsZ share ancestry, the understanding of primitive mechanism of their dynamics will be helpful in the fundamental study of the dynamics of similar structures in higher organisms. The evolution of cytoskeleton from FtsZ to microtubules has been discussed previously (Erickson 2007). Being extremely divergent from their precursor protein FtsZ, tubulins show a high level of conservation across modern eukaryotic species while bacterial FtsZ shows $40-50 \%$ sequence identity across species. FtsZ is considered to be an ancient protein and the division mechanism carried out in the first cellular forms was suggested to be carried out by FtsZ (Davis 2002, Erickson 2007). The process was successful enough to be retained in the modern species of bacteria and archaea (Davis 2002, Erickson 2007). FtsZ is suggested to be the cell division protein in early eukaryotes as well (Doolittle 1995, Doolittle \& York 2002). As evolution from FtsZ to microtubules took place, the functional role of the protein was transformed from cytokinesis to chromosome segregation. The complexities of this evolution might be the reason for the conservation of tubulin across modern eukaryotic species, as it would be difficult for these welldeveloped proteins to undergo further changes (Erickson 2007). This evolution of FtsZ to microtubules involves mutations that allow for binding of microtubule-associated proteins and help to form additional lateral contacts. FtsZ gene duplication in chloroplast and mitochondria of lower eukaryotes further bridges the gap between FtsZ formed by the association of a single subunit and microtubules formed by the association of two classes of subunits. New changes in the curvature advantageous for

Published by Bioscientifica Ltd. 
DNA segregation were developed (Housman et al. 2016). However, the dynamic properties were conserved. New functions were associated to these dynamic cytoskeletal structures giving the modern day microtubules.

Microtubule dynamics have been studied for much longer than FtsZ dynamics; yet, the mechanism for neither has been fully established. New information regarding FtsZ dynamics can enhance our understanding of microtubule dynamics.

Though evidence for the existence of a more dynamic plus end of FtsZ and a less dynamic minus end has surfaced recently (Loose \& Mitchison 2014, BissonFilho et al. 2015), a long-standing question whether FtsZ can exhibit dynamic instability and treadmilling like microtubules remains unanswered. In a recent work, FtsZ treadmilling has been suggested as a mechanism to explain the recruitment of enzymes at the division site (Bisson-Filho et al. 2017). A large body of evidence points toward the similarity of the dynamics of FtsZ and tubulin, thereby providing a platform to study the basic mechanism of the assembly of microtubules through FtsZ.

One such concept is that of the force generation by disassembling filaments. Many studies have tried to determine whether the disassembling FtsZ filaments can generate enough force to cause bending and constriction of the cell membrane. In eukaryotes, the question remains is the force generated by the disassembling microtubules of the spindle apparatus enough to pull the chromosomes apart? The presence of molecular motors associated with the microtubules argues against it. Many other 'passive' forces such as viscous drag, frictional resistance and force generated by bending of the microtubules are proposed to also contribute (Forth \& Kapoor 2017). Without the interference of the associated proteins like in microtubules, FtsZ dynamics can be studied to explain such force generation.

During anaphase, the chromosomes are pulled toward the poles by the disassembling microtubules. Different mechanisms are proposed for the disassembly occurring at only one end like in yeasts (plus end), or both ends like in human mitotic cells, or at the minus end coupled with assembly at the plus end (Asbury 2017). Studies to investigate how the ends of the microtubules switch from assembly states to disassembly state and what drives these changes in correlation to GTP binding and hydrolysis can be based on studies with FtsZ and its disassembly properties, and if present, the ability to treadmill.

The correlation between the processes of nucleotidebinding and filament assembly has been explained differently for FtsZ and tubulin, which further explains their mechanical and functional roles in the cells. Conformational changes also form the basis for explaining the assembly and disassembly of the polymers. However, what drives this change in conformation is little understood and different models are proposed for FtsZ and microtubules. Understanding the dynamics of FtsZ may explain the GTP cap-GDP core model of microtubules.

Overall, these studies provide a platform to discover new drugs and agents that target the two proteins and disrupt their assembly dynamics. Such compounds have a great scope in anticancer and antibacterial therapy.

\section{Declaration of interest}

The authors declare that there is no conflict of interest that could be perceived as prejudicing the impartiality of this review.

\section{Funding}

This work is supported by a grant from Department of Science and Technology, Government of India to D P.

\section{References}

Adelman MR, Borisy GG, Shelanski ML, Weisenberg RC \& Taylor EW 1968 Cytoplasmic filaments and tubules. Federation Proceedings 27 1186-1193.

Akhmanova A \& Steinmetz MO 2015 Control of microtubule organization and dynamics: two ends in the limelight. Nature Reviews Molecular Cell Biology 16 711-726. (doi:10.1038/nrm4084)

Akhtar P, Anand SP, Watkins SC \& Khan SA 2009 The tubulin-like RepX protein encoded by the pXO1 plasmid forms polymers in vivo in bacillus anthracis. Journal of Bacteriology $1912493-2500$. (doi:10.1128/JB.00027-09)

Amos L \& Klug A 1974 Arrangement of subunits in flagellar microtubules. Journal of Cell Science 14 523-549.

Anand SP, Akhtar P, Tinsley E, Watkins SC \& Khan SA 2008 GTP-dependent polymerization of the tubulin-like RepX replication protein encoded by the pXO1 plasmid of Bacillus anthracis. Molecular Microbiology 67 881-890. (doi:10.1111/j.1365-2958.2007.06100.x)

Andreu JM, Schaffner-Barbero C, Huecas S, Alonso D, Lopez-Rodriguez ML, Ruiz-Avila LB, Núñez-Ramírez R, Llorca O \& Martín-Galiano AJ 2010 The antibacterial cell division inhibitor PC190723 is an FtsZ polymer-stabilizing agent that induces filament assembly and condensation. Journal of Biological Chemistry 285 14239-14246. (doi:10.1074/jbc.M109.094722)

Asbury CL 2017 Anaphase A: disassembling microtubules move chromosomes toward spindle poles. Biology 6 15. (doi:10.3390/ biology6010015)

Ayaz P, Ye X, Huddleston P, Brautigam CA \& Rice LM 2012 A TOG: tubulin complex structure reveals conformation-based mechanisms for a microtubule polymerase. Science 337 857-860. (doi:10.1126/ science.1221698)

Ayaz P, Munyoki S, Geyer EA, Piedra F-A, Vu ES, Bromberg R, Otwinowski Z, Grishin N, Brautigam C, Rice L, et al. 2014 A tethered delivery mechanism explains the catalytic action of a microtubule polymerase. eLife 3 e03069. (doi:10.7554/elife.03069)

Aylett CHS, Wang Q, Michie KA, Amos LA \& Lowe J 2010 Filament structure of bacterial tubulin homologue TubZ. PNAS 107 19766-19771. (doi:10.1073/pnas.1010176107) 
Banerjee M, Singh P \& Panda D 2010 Curcumin suppresses the dynamic instability of microtubules, activates the mitotic checkpoint and induces apoptosis in MCF-7 cells. FEBS Journal 277 3437-3448. (doi:10.1111/j.1742-4658.2010.07750.x)

Beech PL, Nheu T, Schultz T, Herbert S, Lithgow T, Gilson PR \& McFadden GI 2000 Mitochondrial FtsZ in a chromophyte alga. Science 287 1276-1279. (doi:10.1126/science.287.5456.1276)

Belletti B \& Baldassarre G 2011 Stathmin: a protein with many tasks. New biomarker and potential target in cancer. Expert Opinion on Therapeutic Targets 15 1249-1266. (doi:10.1517/ 14728222.2011.620951)

Bermudes D, Hinkle G \& Margulis L 1994 Do prokaryotes contain microtubules? Microbiological Reviews 58 387-400.

Beuria TK, Santra MK \& Panda D 2005 Sanguinarine blocks cytokinesis in bacteria by inhibiting FtsZ assembly a bundling. Biochemistry 44 16584-16593. (doi:10.1021/bi050767+)

Beuria TK, Singh P, Surolia A \& Panda D 2009 Promoting assembly and bundling of FtsZ as a strategy to inhibit bacterial cell division: a new approach for developing novel antibacterial drugs. Biochemical Journal 423 61-69. (doi:10.1042/BJ20090817)

Bi E \& Lutkenhaus J 1991 FtsZ ring structure associated with division in Escherichia coli. Nature 354 161-164. (doi:10.1038/354161a0)

Biaoxue R, Xiguang C, Hua L \& Shuanying Y 2016 Stathmin-dependent molecular targeting therapy for malignant tumor: the latest 5 years' discoveries and developments. Journal of Translational Medicine $\mathbf{1 4}$ 279. (doi:10.1186/s12967-016-1000-z)

Bisson-Filho AW, Discola KF, Castellen P, Blasios V, Martins A, Sforça ML, Garcia W, Zeri ACM, Erickson HP, Dessen A, et al. 2015 FtsZ filament capping by MciZ, a developmental regulator of bacterial division. PNAS 112 E2130-E2138. (doi:10.1073/pnas.1414242112)

Bisson-Filho AW, Hsu Y-P, Squyres GR, Kuru E, Wu F, Jukes C, Sun Y, Dekker C, Holden S, VanNieuwenhze MS, et al. 2017 Treadmilling by FtsZ filaments drives peptidoglycan synthesis and bacterial cell division. Science 355 739-743. (doi:10.1126/science.aak9973)

Borisy GG \& Olmsted JB 1972 Nucleated assembly of microtubules in porcine brain extracts. Science 177 1196-1197. (doi:10.1126/ science.177.4055.1196)

Bourne HR, Sanders DA \& McCormick F 1991 The GTPase superfamily: conserved structure and molecular mechanism. Nature 349 117-127. (doi:10.1038/349117a0)

Bramhill D \& Thompson CM 1994 GTP-dependent polymerization of Escherichia coli FtsZ protein to form tubules. PNAS 91 5813-5817. (doi:10.1073/pnas.91.13.5813)

Brouhard GJ \& Rice LM 2014 The contribution of $\alpha \beta$-tubulin curvature to microtubule dynamics. Journal of Cell Biology 207 323-334. (doi:10.1083/jcb.201407095)

Bryan J \& Wilson L 1971 Are cytoplasmic microtubules heteropolymers? PNAS 68 1762-1766. (doi:10.1073/pnas.68.8.1762)

Buey RM, Fernando Díaz J \& Andreu JM 2006 The nucleotide switch of tubulin and microtubule assembly: a polymerization-driven structural change. Biochemistry 45 5933-5938. (doi:10.1021/bi060334m)

Buske PJ \& Levin PA 2013 A flexible C-terminal linker is required for proper FtsZ assembly in vitro and cytokinetic ring formation in vivo. Molecular Microbiology 89 249-263. (doi:10.1111/mmi.12272)

Caplow M \& Fee L 2003 Concerning the chemical nature of tubulin subunits that cap and stabilize microtubules. Biochemistry $\mathbf{4 2}$ 2122-2126. (doi:10.1021/bi027010s)

Carlier MF \& Pantaloni D 1981 Kinetic analysis of guanosine 5 '-triphosphate hydrolysis associated with tubulin polymerization. Biochemistry 20 1918-1924. (doi:10.1021/bi00510a030)

Cavalier-Smith T 2000 Membrane heredity and early chloroplast evolution. Trends in Plant Science 5 174-182. (doi:10.1016/S13601385(00)01598-3)

Chan FY, Sun N, Neves MAC, Lam PCH, Chung WH, Wong LK, Chow HY, Ma DL, Chan PH, Leung YC, et al. 2013 Identification of a new class of FtsZ inhibitors by structure-based design and in vitro screening. Journal of Chemical Information and Modeling $\mathbf{5 3}$ 2131-2140. (doi:10.1021/ci400203f)

Chaudhary V, Venghateri JB, Dhaked HPS, Bhoyar AS, Guchhait SK \& Panda D 2016 Novel Combretastatin-2-aminoimidazole analogues as potent tubulin assembly inhibitors: exploration of unique pharmacophoric impact of bridging skeleton and aryl moiety. Journal of Medicinal Chemistry 59 3439-3451. (doi:10.1021/acs. jmedchem.6b00101)

Chen Y \& Erickson HP 2008 In vitro assembly studies of FtsZ/tubulinlike proteins (TubZ) from Bacillus plasmids: evidence for a capping mechanism. Journal of Biological Chemistry 283 8102-8109. (doi:10.1074/jbc.M709163200)

Chen Y, Bjornson K, Redick SD \& Erickson HP 2005 A rapid fluorescence assay for FtsZ assembly indicates cooperative assembly with a dimer nucleus. Biophysical Journal 88 505-514. (doi:10.1529/ biophysj.104.044149)

Chrétien D, Fuller SD \& Karsenti E 1995 Structure of growing microtubule ends: two-dimensional sheets close into tubes at variable rates. Journal of Cell Biology 129 1311-1328. (doi:10.1083/ jcb.129.5.1311)

Coombes CE, Yamamoto A, Kenzie MR, Odde DJ \& Gardner MK 2013 Evolving tip structures can explain age-dependent microtubule catastrophe. Current Biology 23 1342-1348. (doi:10.1016/j. cub.2013.05.059)

Cordell SC, Robinson EJH \& Lowe J 2003 Crystal structure of the SOS cell division inhibitor SulA and in complex with FtsZ. PNAS 100 7889-7894. (doi:10.1073/pnas.1330742100)

David-Pfeuty T, Erickson HP \& Pantaloni D 1977 Guanosinetriphosphatase activity of tubulin associated with microtubule assembly. PNAS 74 5372-5376. (doi:10.1073/ pnas.74.12.5372)

Davis BK 2002 Molecular evolution before the origin of species. Progress in Biophysics and Molecular Biology 79 77-133. (doi:10.1016/S00796107(02)00012-3)

de Boer P, Crossley R \& Rothfield L 1992 The essential bacterial celldivision protein FtsZ is a GTPase. Nature 359 254-256. (doi:10.1038/359254a0)

De Pereda JM, Leynadier D, Evangelio JA, Chacón P \& Andreu JM 1996 Tubulin secondary structure analysis, limited proteolysis sites, and homology to FtsZ. Biochemistry 35 14203-14215. (doi:10.1021/ bi961357b)

Dehmelt L \& Halpain S 2005 The MAP2/Tau family of microtubuleassociated proteins. Genome Biology 6 204. (doi:10.1186/ gb-2004-6-1-204)

Desai A \& Mitchison TJ 1997 Microtubule polymerization dynamics. Annual Review of Cell and Developmental Biology 13 83-117. (doi:10.1186/gb-2004-6-1-204)

Domadia P, Swarup S, Bhunia A, Sivaraman J \& Dasgupta D 2007 Inhibition of bacterial cell division protein FtsZ by cinnamaldehyde. Biochemical Pharmacology 74 831-840. (doi:10.1016/j. bcp.2007.06.029)

Doolittle RF 1995 The origins and evolution of eukaryotic proteins. Philosophical Transactions of the Royal Society of London Series B Biological Sciences 349 235-240. (doi:10.1098/rstb.1995.0107)

Doolittle RF \& York AL 2002 Bacterial actins? An evolutionary perspective. BioEssays 24 293-296. (doi:10.1002/bies.10079)

Dorleans A, Gigant B, Ravelli RBG, Mailliet P, Mikol V \& Knossow M 2009 Variations in the colchicine-binding domain provide insight into the structural switch of tubulin. PNAS 106 13775-13779. (doi:10.1073/pnas.0904223106)

Duggin IG, Aylett CHS, Walsh JC, Michie KA, Wang Q, Turnbull L, Dawson EM, Harry EJ, Whitchurch CB, Amos LA, et al. 2015 CetZ tubulin-like proteins control archaeal cell shape. Nature $\mathbf{5 1 9}$ 362-365. (doi:10.1038/nature13983)
๑ 2017 Society for Endocrinology Printed in Great Britain
Published by Bioscientifica Ltd 
Erickson HP 1974a Assembly of microtubules from preformed, ringshaped protofilaments and 6-s tubulin. Journal of Supramolecular Structure 2 393-411. (doi:10.1002/jss.400020228)

Erickson HP 1974b Microtubule surface lattice and subunit structure and observations on reassembly. Journal of Cell Biology 60 153-167. (doi:10.1083/jcb.60.1.153)

Erickson HP 1995 FtsZ, a prokaryotic homolog of tubulin? Cell 80 367-370. (doi:10.1083/jcb.60.1.153)

Erickson H 1997 FtsZ, a tubulin homologue in prokaryote cell division. Trends in Cell Biology 7 362-367. (doi:10.1016/S09628924(97)01108-2)

Erickson HP 1998 Atomic structures of tubulin and FtsZ. Trends in Cell Biology 8 133-137. (doi:10.1016/S0962-8924(98)01237-9)

Erickson HP 2007 Evolution of the cytoskeleton. BioEssays 29 668-677. (doi:10.1002/bies.20601)

Erickson HP \& O'Brien ET 1992 Microtubule dynamic instability and GTP hydrolysis. Annual Review of Biophysics and Biomolecular Structure 21 145-166. (doi:10.1146/annurev.bb.21.060192.001045)

Erickson HP \& Stoffler D 1996 Protofilaments and rings, two conformations of the tubulin family conserved from bacterial FtsZ to alpha/beta and gamma tubulin. Journal of Cell Biology 135 5-8. (doi:10.1083/jcb.135.1.5)

Erickson HP, Taylor DW, Taylor KA \& Bramhill D 1996 Bacterial cell division protein FtsZ assembles into protofilament sheets and minirings, structural homologs of tubulin polymers. PNAS 93 519-523. (doi:10.1073/pnas.93.1.519)

Erickson HP, Anderson DE \& Osawa M 2010 FtsZ in bacterial cytokinesis: cytoskeleton and force generator all in one. Microbiology and Molecular Biology Reviews 74 504-528. (doi:10.1128/ MMBR.00021-10)

Fan J, Griffiths AD, Lockhart A, Cross RA \& Amos LA 1996 Microtubule minus ends can be labelled with a phage display antibody specific to alpha-tubulin. Journal of Molecular Biology 259 325-330. (doi:10.1006/jmbi.1996.0322)

Field JJ, Kanakkanthara A \& Miller JH 2014 Microtubule-targeting agents are clinically successful due to both mitotic and interphase impairment of microtubule function. Bioorganic and Medicinal Chemistry 22 5050-5059. (doi:10.1016/j.bmc.2014.02.035)

Findeisen P, Muhlhausen S, Dempewolf S, Hertzog J, Zietlow A, Carlomagno T \& Kollmar M 2014 Six subgroups and extensive recent duplications characterize the evolution of the eukaryotic tubulin protein family. Genome Biology and Evolution 6 2274-2288. (doi:10.1093/gbe/evu187)

Fleurie A, Lesterlin C, Manuse S, Zhao C, Cluzel C, Lavergne J-P, FranzWachtel M, Macek B, Comber C, Kuru E, et al. 2014 MapZ marks the division sites and positions FtsZ rings in Streptococcus pneumoniae. Nature 516 259-262. (doi:10.1038/nature13966)

Forth S \& Kapoor TM 2017 The mechanics of microtubule networks in cell division. Journal of Cell Biology 216 1525-1531. (doi:10.1083/ jcb.201612064)

Gigant B, Wang C, Ravelli RBG, Roussi F, Steinmetz MO, Curmi PA, Sobel A \& Knossow M 2005 Structural basis for the regulation of tubulin by vinblastine. Nature $\mathbf{4 3 5}$ 519-522. (doi:10.1038/ nature03566)

Gray MW 1999 Evolution of organellar genomes. Current Opinion in Genetics and Development 9 678-687. (doi:10.1016/S0959437X(99)00030-1)

Grishchuk EL, Molodtsov MI, Ataullakhanov FI \& McIntosh JR 2005 Force production by disassembling microtubules. Nature $\mathbf{4 3 8}$ 384-388. (doi:10.1038/nature04132)

Groundwater PW, Narlawar R, Liao VWY, Bhattacharya A, Srivastava S, Kunal K, Doddareddy M, Oza PM, Mamidi R, Marrs ECL, et al. 2017 A carbocyclic curcumin inhibits proliferation of gram-positive bacteria by targeting FtsZ. Biochemistry 56 514-524. (doi:10.1021/acs. biochem.6b00879)

Haeusser DP \& Margolin W 2016 Splitsville: structural and functional insights into the dynamic bacterial Z ring. Nature Reviews Microbiology 14 305-319. (doi:10.1038/nrmicro.2016.26)

Haydon DJ, Stokes NR, Ure R, Galbraith G, Bennett JM, Brown DR, Baker PJ, Barynin VV, Rice DW, Sedelnikova SE, et al. 2008 An inhibitor of FtsZ with potent and selective anti-staphylococcal activity. Science 321 1673-1675. (doi:10.1126/science.1159961)

He X, Li S, Huang H, Li Z, Chen L, Ye S, Huang J, Zhan J \& Lin T 2011 A pharmacokinetic and safety study of single dose intravenous combretastatin A4 phosphate in Chinese patients with refractory solid tumours. British Journal of Clinical Pharmacology 71 860-870. (doi:10.1111/j.1365-2125.2011.03928.x)

Hesse J, Thierauf M \& Ponstingl H 1987 Tubulin sequence region beta $155-174$ is involved in binding exchangeable guanosine triphosphate. Journal of Biological Chemistry 262 15472-15475.

Higuchi T \& Uhlmann F 2005 Stabilization of microtubule dynamics at anaphase onset promotes chromosome segregation. Nature $\mathbf{4 3 3}$ 171-176. (doi:10.1038/nature03240)

Hill TL \& Carlier MF 1983 Steady-state theory of the interference of GTP hydrolysis in the mechanism of microtubule assembly. PNAS $\mathbf{8 0}$ 7234-7238. (doi:10.1073/pnas.80.23.7234)

Hirose K, Fan J \& Amos LA 1995 Re-examination of the polarity of microtubules and sheets decorated with kinesin motor domain. Journal of Molecular Biology 251 329-333. (doi:10.1006/jmbi.1995.0437)

Hirota Y, Ryter A \& Jacob F 1968 Thermosensitive mutants of E. coli affected in the processes of DNA synthesis and cellular division. Cold Spring Harbor Symposia on Quantitative Biology 33 677-693. (doi:10.1101/SQB.1968.033.01.077)

Holden SJ, Pengo T, Meibom KL, Fernandez Fernandez C, Collier J \& Manley S 2014 High throughput 3D super-resolution microscopy reveals Caulobacter crescentus in vivo Z-ring organization. PNAS 111 4566-4571. (doi:10.1073/pnas.1313368111)

Horio T \& Hotani H 1986 Visualization of the dynamic instability of individual microtubules by dark-field microscopy. Nature $\mathbf{3 2 1}$ 605-607. (doi:10.1038/321605a0)

Housman M, Milam SL, Moore DA, Osawa M \& Erickson HP 2016 FtsZ protofilament curvature is the opposite of tubulin rings. Biochemistry 55 4085-4091. (doi:10.1021/acs.biochem.6b00479)

Howard J \& Hyman AA 2007 Microtubule polymerases and depolymerases. Current Opinion in Cell Biology 19 31-35. (doi:10.1016/j.ceb.2006.12.009)

Huang Q, Kirikae F, Kirikae T, Pepe A, Amin A, Respicio L, Slayden RA, Tonge PJ \& Ojima I 2006 Targeting FtsZ for antituberculosis drug discovery: noncytotoxic taxanes as novel antituberculosis agents. Journal of Medicinal Chemistry 49 463-466. (doi:10.1021/jm050920y)

Huecas S \& Andreu JM 2003 Energetics of the cooperative assembly of cell division protein FtsZ and the nucleotide hydrolysis switch. Journal of Biological Chemistry 278 46146-46154. (doi:10.1074/jbc. M307128200)

Hurley KA, Santos TMA, Nepomuceno GM, Huynh V, Shaw JT \& Weibel DB 2016 Targeting the bacterial division protein FtsZ. Journal of Medicinal Chemistry 59 6975-6998. (doi:10.1021/acs.jmedchem.5b01098)

Ishikawa S, Kawai Y, Hiramatsu K, Kuwano M \& Ogasawara N 2006 A new FtsZ-interacting protein, YlmF, complements the activity of FtsA during progression of cell division in Bacillus subtilis. Molecular Microbiology 60 1364-1380. (doi:10.1111/j.1365-2958.2006.05184.x)

Jacq M, Adam V, Bourgeois D, Moriscot C, Di Guilmi AM, Vernet T \& Morlot C 2015 Remodeling of the Z-ring nanostructure during the Streptococcus pneumoniae cell cycle revealed by photoactivatedlocalization microscopy. mBio 6 e01108-e01115. (doi:10.1128/mbio.01108-15) http://erc.endocrinology-journals.org

DOI: $10.1530 /$ ERC-17-0118
C 2017 Society for Endocrinology Printed in Great Britain
Published by Bioscientifica Ltd 
Jenkins C, Samudrala R, Anderson I, Hedlund BP, Petroni G, Michailova N, Pinel N, Overbeek R, Rosati G \& Staley JT 2002 Genes for the cytoskeletal protein tubulin in the bacterial genus Prosthecobacter. PNAS 99 17049-17054. (doi:10.1073/pnas.012516899)

Jindal B \& Panda D 2013 Understanding FtsZ assembly: cues from the behavior of its N- and C-terminal domains. Biochemistry 52 7071-7081. (doi:10.1021/bi400129j)

Jordan MA \& Wilson L. 2004 Microtubules as a target for anticancer drugs. Nature Reviews Cancer 4 253-265. (doi:10.1038/nrc1317)

Joshi HC 1994 Microtubule organizing centers and $\gamma$-tubulin. Current Opinion in Cell Biology 6 55-62. (doi:10.1016/0955-0674(94)90116-3)

Kapoor S \& Panda D 2009 Targeting FtsZ for antibacterial therapy: a promising avenue. Expert Opinion on Therapeutic Targets 13 1037-1051. (doi:10.1517/14728220903173257)

Keeling PJ \& Doolittle WF 1995 Archaea: narrowing the gap between prokaryotes and eukaryotes. PNAS 92 5761-5764. (doi:10.1073/ pnas.92.13.5761)

Kirschner MW, Williams RC, Weingarten M \& Gerhart JC 1974 Microtubules from mammalian brain: some properties of their depolymerization Products and a proposed mechanism of assembly and disassembly. PNAS 71 1159-1163. (doi:10.1073/pnas.71.4.1159)

Kline-Smith SL \& Walczak CE 2004 Mitotic spindle assembly and chromosome segregation: refocusing on microtubule dynamics. Molecular Cell 15 317-327. (doi:10.1016/j.molcel.2004.07.012)

Kuchibhatla A, Bhattacharya A \& Panda D 2011 ZipA binds to FtsZ with high affinity and enhances the stability of FtsZ protofilaments. PLoS ONE 6 e28262. (doi:10.1371/journal.pone.0028262)

Kueh HY \& Mitchison T 2009 Structural plasticity in actin and tubulin polymer dynamics. Science 325 960-963. (doi:10.1126/ science.1168823)

Kumar K, Awasthi D, Berger WT, Tonge PJ, Slayden RA \& Ojima I 2010 Discovery of anti-TB agents that target the cell-division protein FtsZ. Future Medicinal Chemistry 2 1305-1323. (doi:10.4155/fmc.10.220)

Kwon M \& Scholey JM 2004 Spindle mechanics and dynamics during mitosis in Drosophila. Trends in Cell Biology 14 194-205. (doi:10.1016/j.tcb.2004.03.003)

Lan G, Daniels BR, Dobrowsky TM, Wirtz D \& Sun SX 2009 Condensation of FtsZ filaments can drive bacterial cell division. PNAS 106 121-126. (doi:10.1073/pnas.0807963106)

Läppchen T, Pinas VA, Hartog AF, Koomen GJ, Schaffner-Barbero C, Andreu JM, et al. 2008 Probing FtsZ and tubulin with C8-substituted GTP analogs reveals differences in their nucleotide binding sites. Chemistry and Biology 15 189-199. (doi:10.1016/j. chembiol.2007.12.013)

Larsen RA, Cusumano C, Fujioka A, Lim-Fong G, Patterson P \& Pogliano J 2007 Treadmilling of a prokaryotic tubulin-like protein, TubZ, required for plasmid stability in Bacillus thuringiensis. Genes and Development 21 1340-1352. (doi:10.1101/gad.1546107)

Ledbetter MC \& Porter KR 1964 Morphology of microtubules of plant cell. Science 144 872-874. (doi:10.1126/science.144.3620.872)

Li Z, Trimble MJ, Brun YV \& Jensen GJ 2007 The structure of FtsZ filaments in vivo suggests a force-generating role in cell division. EMBO Journal 26 4694-4708. (doi:10.1038/sj.emboj.7601895)

Logarinho E, Bousbaa H, Dias JM, Lopes C, Amorim I, Antunes-Martins A \& Sunkel CE 2004 Different spindle checkpoint proteins monitor microtubule attachment and tension at kinetochores in Drosophila cells. Journal of Cell Science 117 1757-1771. (doi:10.1242/jcs.01033)

Loose M \& Mitchison TJ 2014 The bacterial cell division proteins FtsA and FtsZ self-organize into dynamic cytoskeletal patterns. Nature Cell Biology 16 38-46. (doi:10.1038/ncb2885)

Löwe J \& Amos LA 1998 Crystal structure of the bacterial cell-division protein FtsZ. Nature 391 203-206.

Löwe J, Li H, Downing K \& Nogales E 2001 Refined structure of $\alpha \beta$-tubulin at $3.5 \AA$ resolution. Journal of Molecular Biology $\mathbf{3 1 3}$ 1045-1057. (doi:10.1006/jmbi.2001.5077)
Lu C, Stricker J \& Erickson HP 1998 FtsZ from Escherichia coli, Azotobacter vinelandii, and Thermotoga maritima - quantitation, GTP hydrolysis, and assembly. Cell Motility and the Cytoskeleton 40 71-86. (doi:10.1002/(SICI)1097-0169(1998)40: $1<71:$ :AID-CM7>3.0.CO;2-I)

Lu C, Reedy M \& Erickson HP 2000 Straight and curved conformations of FtsZ are regulated by GTP hydrolysis. Journal of Bacteriology 182 164-170. (doi:10.1128/JB.182.1.164-170.2000)

Lutkenhaus JF 1983 Coupling of DNA replication and cell division: sulB is an allele of ftsZ. Journal of Bacteriology 154 1339-1346.

Lutkenhaus JF \& Donachie WD 1979 Identification of the ftsA gene product. Journal of Bacteriology 137 1088-1094.

Lutkenhaus JF, Wolf-Watz H \& Donachie WD 1980 Organization of genes in the ftsA-envA region of the Escherichia coli genetic map and identification of a new fts locus (ftsZ). Journal of Bacteriology 142 615-620.

Ma X \& Margolin W 1999 Genetic and functional analyses of the conserved C-terminal core domain of Escherichia coli FtsZ. Journal of Bacteriology 181 7531-7544.

Ma X, Ehrhardt DW \& Margolin W 1996 Colocalization of cell division proteins FtsZ and FtsA to cytoskeletal structures in living Escherichia coli cells by using green fluorescent protein. PNAS 93 12998-13003. (doi:10.1073/pnas.93.23.12998)

Maccioni RB \& Cambiazo V 1995 Role of microtubule-associated proteins in the control of microtubule assembly. Physiological Reviews 75 835-864.

Mahendran R, Jenifer FJ, Palanimuthu M \& Subasri S 2011 Sequence and structural analysis of FtsZ homologs and comparison of bacterial FTsZ with eukaryotic tubulins. Indian Journal of Science and Technology 4 141-146.

Mandelkow E, Mandelkow E \& Milligan RA 1991 Microtubule dynamics and microtubule caps: a time-resolved cryo-electron microscopy study. Journal of Cell Biology 114 977-991. (doi:10.1083/ jcb.114.5.977)

Margolin W 2000 Themes and variations in prokaryotic cell division. FEMS Microbiology Reviews 24 531-548. (doi:10.1111/ j.1574-6976.2000.tb00554.x)

Margolin W 2005 FtsZ and the division of prokaryotic cells and organelles. Nature Reviews Molecular Cell Biology 6 862-871. (doi:10.1038/nrm1745)

Margolin W, Wang R \& Kumar M 1996 Isolation of an ftsZ homolog from the archaebacterium Halobacterium salinarium: implications for the evolution of FtsZ and tubulin. Journal of Bacteriology $\mathbf{1 7 8}$ 1320-1327. (doi:10.1128/jb.178.5.1320-1327.1996)

Margolis RL \& Wilson L 1978 Opposite end assembly and disassembly of microtubules at steady state in vitro. Cell $\mathbf{1 3} 1-8$. (doi:10.1016/0092-8674(78)90132-0)

Massidda O, Nováková L \& Vollmer W 2013 From models to pathogens: how much have we learned about Streptococcus pneumoniae cell division? Environmental Microbiology 15 3133-3157. (doi:10.1111/1462-2920.12189)

McFadden GI 2001 Primary and secondary endosymbiosis and the origin of plastids. Journal of Phycology 37 951-959. (doi:10.1046/j.1529-8817.2001.01126.x)

McIntosh JR, Volkov V, Ataullakhanov FI \& Grishchuk EL 2010 Tubulin depolymerization may be an ancient biological motor. Journal of Cell Science 123 3425-3434. (doi:10.1242/jcs.067611)

Melki R, Carlier M-F, Pantaloni D \& Timasheff SN 1989 Cold depolymerization of microtubules to double rings: geometric stabilization of assemblies. Biochemistry 28 9143-9152. (doi:10.1021/ bi00449a028)

Mingorance J, Rueda S, Gómez-Puertas P, Valencia A \& Vicente M 2001 Escherichia coli FtsZ polymers contain mostly GTP and have a high nucleotide turnover. Molecular Microbiology 41 83-91. (doi:10.1046/j.1365-2958.2001.02498.x) http://erc.endocrinology-journals.org

DOI: $10.1530 /$ ERC-17-0118
(C) 2017 Society for Endocrinology Printed in Great Britain
Published by Bioscientifica Ltd 
Mitchison TJ 1993 Localization of an exchangeable GTP binding site at the plus end of microtubules. Science 261 1044-1048. (doi:10.1126/ science.8102497)

Mitchison T \& Kirschner M 1984 Dynamic instability of microtubule growth. Nature 312 237-242. (doi:10.1038/312237a0)

Miyagishima S, Nozaki H, Nishida K, Nishida K, Matsuzaki M \& Kuroiwa T 2004 Two types of FtsZ proteins in mitochondria and red-lineage chloroplasts: the duplication of FtsZ is implicated in endosymbiosis. Journal of Molecular Evolution 58 291-303. (doi:10.1007/s00239-0032551-1)

Mohan R \& Panda D 2008 Kinetic stabilization of microtubule dynamics by estramustine is associated with tubulin acetylation, spindle abnormalities, and mitotic arrest. Cancer Research 68 6181-6189. (doi:10.1158/0008-5472.CAN-08-0584)

Mukherjee A \& Lutkenhaus J 1998 Dynamic assembly of FtsZ regulated by GTP hydrolysis. EMBO Journal 17 462-469. (doi:10.1093/ emboj/17.2.462)

Mukherjee A, Dai K \& Lutkenhaus J 1993 Escherichia coli cell division protein FtsZ is a guanine nucleotide binding protein. PNAS $\mathbf{9 0}$ 1053-1057. (doi:10.1073/pnas.90.3.1053)

Nawrotek A, Knossow M \& Gigant B 2011 The determinants that govern microtubule assembly from the atomic structure of GTP-Tubulin. Journal of Molecular Biology 412 35-42. (doi:10.1016/j. jmb.2011.07.029)

Ni L, Xu W, Kumaraswami M \& Schumacher MA 2010 Plasmid protein TubR uses a distinct mode of HTH-DNA binding and recruits the prokaryotic tubulin homolog TubZ to effect DNA partition. PNAS 107 11763-11768. (doi:10.1073/pnas.1003817107)

Nishida K, Takahara M, Miyagishima S, Kuroiwa H, Matsuzaki M \& Kuroiwa T 2003 Dynamic recruitment of dynamin for final mitochondrial severance in a primitive red alga. PNAS $\mathbf{1 0 0}$ 2146-2151. (doi:10.1073/pnas.0436886100)

Niu L \& Yu J 2008 Investigating intracellular dynamics of FtsZ cytoskeleton with photoactivation single-molecule tracking. Biophysical Journal 95 2009-2016. (doi:10.1529/biophysj.108.128751)

Nogales E 2001 Structural insights into microtubule function. Annual Review of Biophysics and Biomolecular Structure 30 397-420. (doi:10.1146/annurev.biophys.30.1.397)

Nogales E \& Wang H-W 2006 Structural mechanisms underlying nucleotide-dependent self-assembly of tubulin and its relatives. Current Opinion in Structural Biology 16 221-229. (doi:10.1016/j. sbi.2006.03.005)

Nogales E, Downing KH, Amos LA \& Löwe J 1998a Tubulin and FtsZ form a distinct family of GTPases. Nature Structural Biology 5 451-458. (doi:10.1038/nsb0698-451)

Nogales E, Wolf SG \& Downing KH 1998b Structure of the $\alpha \beta$ tubulin dimer by electron crystallography. Nature 391 199-203. (doi:10.1038/34465)

Oakley BR 1995 A nice ring to the centrosome. Nature 378 555-556. (doi:10.1038/378555a0)

Ojima I, Kumar K, Awasthi D \& Vineberg JG 2014 Drug discovery targeting cell division proteins, microtubules and FtsZ. Bioorganic and Medicinal Chemistry 22 5060-5077. (doi:10.1016/j.bmc.2014.02.036)

Oliva MA, Huecas S, Palacios JM, Martín-Benito J, Valpuesta JM \& Andreu JM 2003 Assembly of archaeal cell division protein FtsZ and a GTPase-inactive mutant into double-stranded filaments. Journal of Biological Chemistry 278 33562-33570. (doi:10.1074/jbc. M303798200)

Oliva MA, Cordell SC \& Löwe J 2004 Structural insights into FtsZ protofilament formation. Nature Structural and Molecular Biology 11 1243-1250. (doi:10.1038/nsmb855)

Olson BJSC, Wang Q \& Osteryoung KW 2010 GTP-dependent heteropolymer formation and bundling of chloroplast FtsZ1 and FtsZ2. Journal of Biological Chemistry 285 20634-20643. (doi:10.1074/ jbc.M110.122614)
Ortiz C, Natale P, Cueto L \& Vicente M 2016 The keepers of the ring: regulators of FtsZ assembly. FEMS Microbiology Reviews 40 57-67. (doi:10.1093/femsre/fuv040)

Osawa M, Anderson DE \& Erickson HP 2008 Reconstitution of contractile FtsZ rings in liposomes. Science 320 792-794. (doi:10.1126/science.1154520)

Osawa M, Anderson DE \& Erickson HP 2009 Curved FtsZ protofilaments generate bending forces on liposome membranes. EMBO Journal $\mathbf{2 8}$ 3476-3484. (doi:10.1038/emboj.2009.277)

Osteryoung KW \& McAndrew RS 2001 The plastid division machine. Annual Review of Plant Physiology and Plant Molecular Biology 52 315-333. (doi:10.1146/annurev.arplant.52.1.315)

Osteryoung KW, Stokes KD, Rutherford SM, Percival AL \& Lee WY 1998 Chloroplast division in higher plants requires members of two functionally divergent gene families with homology to bacterial ftsZ. Plant Cell 10 1991-2004. (doi:10.1105/tpc.10.12.1991)

Oxberry ME, Geary TG, Winterrowd CA \& Prichard RK 2001 Individual Expression of recombinant $\alpha$ - and $\beta$-Tubulin from Haemonchus contortus: polymerization and drug effects. Protein Expression and Purification 21 30-39. (doi:10.1006/prep.2000.1347)

Panda D, Miller HP, Islam K \& Wilson L 1997 Stabilization of microtubule dynamics by estramustine by binding to a novel site in tubulin: a possible mechanistic basis for its antitumor action. PNAS 94 10560-10564. (doi:10.1073/pnas.94.20.10560)

Panda D, Miller HP \& Wilson L 2002 Determination of the size and chemical nature of the stabilizing 'cap' at microtubule ends using modulators of polymerization dynamics. Biochemistry 41 1609-1617. (doi:10.1021/bi011767m)

Panda D, Bhattacharya D, Gao QH, Oza PM, Lin H-YJ, Hawkins B, Hibbs DE \& Groundwater PW 2016 Identification of agents targeting FtsZ assembly. Future Medicinal Chemistry 8 1111-1132. (doi:10.4155/fmc2016-0041)

Parker AL, Kavallaris M \& McCarroll JA 2014 Microtubules and their role in cellular stress in cancer. Frontiers in Oncology 4153.

Pazos M, Natale P \& Vicente M 2013 A specific role for the ZipA protein in cell division: stabilization of the FtsZ protein. Journal of Biological Chemistry 288 3219-26. (doi:10.1074/jbc.M112.434944)

Pilhofer M, Ladinsky MS, McDowall AW, Petroni G. \& Jensen GJ 2011 Microtubules in bacteria: ancient tubulins build a five-protofilament homolog of the eukaryotic cytoskeleton. PLoS Biology 9 e1001213. (doi:10.1371/journal.pbio.1001213)

Purich DL \& MacNeal RK 1978 Properties of Tubulin treated with alkaline phosphatase to remove guanine nucleotides from the exchangeable binding site. FEBS Letters 96 83-86. (doi:10.1016/00145793(78)81067-9)

Rai D, Singh JK, Roy N \& Panda D 2008 Curcumin inhibits FtsZ assembly: an attractive mechanism for its antibacterial activity. Biochemical Journal 410 147-155. (doi:10.1042/BJ20070891)

Rai A, Gupta TK, Kini S, Kunwar A, Surolia A \& Panda D 2013 CXIbenzo-84 reversibly binds to tubulin at colchicine site and induces apoptosis in cancer cells. Biochemical Pharmacology 86 378-391. (doi:10.1016/j.bcp.2013.05.024)

Raskin DM \& de Boer PA 1999 Rapid pole-to-pole oscillation of a protein required for directing division to the middle of Escherichia coli. PNAS 96 4971-4976. (doi:10.1073/pnas.96.9.4971)

Ravelli RBG, Gigant B, Curmi PA, Jourdain I, Lachkar S, Sobel A \& Knossow M 2004 Insight into tubulin regulation from a complex with colchicine and a stathmin-like domain. Nature 428 198-202. (doi:10.1038/nature02393)

Ray S, Dhaked HPS \& Panda D 2014 Antimicrobial peptide CRAMP (16-33) stalls bacterial cytokinesis by inhibiting FtsZ assembly. Biochemistry 53 6426-6429. (doi:10.1021/bi501115p)

Ray S, Jindal B, Kunal K, Surolia A \& Panda D 2015 BT-benzo-29 inhibits bacterial cell proliferation by perturbing FtsZ assembly. FEBS Journal 282 4015-4033. (doi:10.1111/febs.13403) http://erc.endocrinology-journals.org

DOI: $10.1530 /$ ERC-17-0118
(C) 2017 Society for Endocrinology Printed in Great Britain
Published by Bioscientifica Ltd. 
RayChaudhuri D 1999 ZipA is a MAP-Tau homolog and is essential for structural integrity of the cytokinetic FtsZ ring during bacterial cel division. EMBO Journal 18 2372-2383. (doi:10.1093/ emboj/18.9.2372)

RayChaudhuri D \& Park JT 1992 Escherichia coli cell-division gene ftsZ encodes a novel GTP-binding protein. Nature 359 251-254. (doi:10.1038/359251a0)

Rice LM, Montabana EA \& Agard DA 2008 The lattice as allosteric effector: structural studies of alphabeta- and gamma-tubulin clarify the role of GTP in microtubule assembly. PNAS 105 5378-5383. (doi:10.1073/pnas.0801155105)

Rieder CL, Davison EA, Jensen LCW, Cassimeris L \& Salmon ED 1986 Oscillatory movements of monooriented chromosomes and their position relative to the spindle pole result from the ejection properties of the aster and half-spindle. Journal of Cell Biology $\mathbf{1 0 3}$ 581-591. (doi:10.1083/jcb.103.2.581)

Rieder CL, Schultz A, Cole R \& Sluder G 1994 Anaphase onset in vertebrate somatic cells is controlled by a checkpoint that monitors sister kinetochore attachment to the spindle. Journal of Cell Biology 127 1301-1310. (doi:10.1083/jcb.127.5.1301)

Rivas G, López A, Mingorance J, Ferrándiz MJ, Zorrilla S, Minton AP, Vicente M \& Andreu JM 2000 Magnesium-induced linear selfassociation of the FtsZ bacterial cell division protein monomer. The primary steps for FtsZ assembly. Journal of Biological Chemistry $\mathbf{2 7 5}$ 11740-11749. (doi:10.1074/jbc.275.16.11740)

Romberg L \& Levin PA 2003 Assembly dynamics of the bacterial cell division protein FtsZ: poised at the edge of stability. Annual Review of Microbiology 57 125-154. (doi:10.1146/annurev. micro.57.012903.074300)

Romberg L \& Mitchison TJ 2004 Rate-limiting guanosine 5'-triphosphate hydrolysis during nucleotide turnover by FtsZ, a prokaryotic tubulin homologue involved in bacterial cell division. Biochemistry $\mathbf{4 3}$ 282-288. (doi:10.1021/bi035465r)

Romberg L, Simon M \& Erickson HP 2001 Polymerization of FtsZ, a bacterial homolog of tubulin. Is assembly cooperative?. Journal of Biological Chemistry 276 11743-11753. (doi:10.1074/jbc. M009033200)

Rothfield L, Justice S \& García-Lara J 1999 Bacterial cell division. Annual Review of Genetics 33 423-448. (doi:10.1146/annurev. genet.33.1.423)

Rowlett VW \& Margolin W 2014 3D-SIM Super-resolution of FtsZ and its membrane tethers in Escherichia coli cells. Biophysical Journal $\mathbf{1 0 7}$ L17-L20. (doi:10.1016/j.bpj.2014.08.024)

Ruiz-Avila LB, Huecas S, Artola M, Vergoñós A, Ramírez-Aportela E, Cercenado E, Barasoain I, Vàzquez-Vila $\mathrm{H}$, Martín-Fontecha $\mathrm{M}$, Chacón P, et al. 2013 Synthetic inhibitors of bacterial cell division targeting the GTP-binding site of FtsZ. ACS Chemical Biology 8 2072-2083. (doi:10.1021/cb400208z)

Rustin GJS, Galbraith SM, Anderson H, Stratford M, Folkes LK, Sena L, Gumbrell L \& Price PM 2003 Phase I clinical trial of weekly combretastatin A4 phosphate: clinical and pharmacokinetic results. Journal of Clinical Oncology 21 2815-22. (doi:10.1200/ JCO.2003.05.185)

Santra MK, Beuria TK, Banerjee A \& Panda D 2004 Ruthenium redinduced bundling of bacterial cell division protein, FtsZ. Journal of Biological Chemistry 279 25959-25965. (doi:10.1074/jbc. M312473200)

Scheffers D-J \& Driessen AJM 2001 The polymerization mechanism of the bacterial cell division protein FtsZ. FEBS Letters 506 6-10. (doi:10.1016/S0014-5793(01)02855-1)

Schiff PB, Fant J \& Horwitz SB 1979 Promotion of microtubule assembly in vitro by taxol. Nature 277 665-667. (doi:10.1038/277665a0)

Schlieper D, Oliva A, Andreu M \& Lo J 2005 Structure of bacterial tubulin BtubA B : evidence for horizontal gene transfer. Molecular Biology 102 170-9175.
Serrano L, De J, Torre L \& Maccioni RB 1984 Involvement of the carboxyl-terminal domain of tubulin in the regulation of its assembly. Biochemistry 81 5989-5993. (doi:10.1073/pnas.81.19.5989)

Singh JK, Makde RD, Kumar V \& Panda D 2007 A membrane protein, EzrA, regulates assembly dynamics of FtsZ by interacting with the C-Terminal tail of FtsZ. Biochemistry 46 11013-11022. (doi:10.1021/ bi700710j)

Singh JK, Makde RD, Kumar V \& Panda D 2008a SepF increases the assembly and bundling of FtsZ polymers and stabilizes FtsZ protofilaments by binding along its length. Journal of Biological Chemistry 283 31116-31124. (doi:10.1074/jbc.M805910200)

Singh P, Rathinasamy K, Mohan R \& Panda D 2008 $b$ Microtubule assembly dynamics: an attractive target for anticancer drugs. IUBMB Life 60 368-375. (doi:10.1002/iub.42)

Singh P, Jindal B, Surolia A \& Panda D 2012 A rhodanine derivative CCR-11 inhibits bacterial proliferation by inhibiting the assembly and GTPase activity of FtsZ. Biochemistry 51 5434-5442. (doi:10.1021/bi201813u)

Singh D, Bhattacharya A, Rai A, Dhaked HPS, Awasthi D, Ojima I \& Panda D 2014 SB-RA-2001 inhibits bacterial proliferation by targeting FtsZ assembly. Biochemistry 53 2979-2992. (doi:10.1021/bi401356y)

Sontag CA, Staley JT \& Erickson HP 2005 In vitro assembly and GTP hydrolysis by bacterial. Journal of Cell Biology 169 35-36. (doi:10.1083/jcb.200502104)

Sossong TM, Brigham-Burke MR, Hensley P \& Pearce KH 1999 Selfactivation of guanosine triphosphatase activity by oligomerization of the bacterial cell division protein FtsZ. Biochemistry 38 14843-14850. (doi:10.1021/bi990917e)

Spiegelman BM, Penningroth SM \& Kirschner MW 1977 Turnover of tubulin and the N site GTP in chinese hamster ovary cells. Cell 12 587-600. (doi:10.1016/0092-8674(77)90259-8)

Sternlicht H, Yaffe MB \& Farr GW 1987 A model of the nucleotidebinding site in tubulin. FEBS Letters 214 226-235. (doi:10.1016/0014-5793(87)80061-3)

Stevenson JP, Rosen M, Sun W, Gallagher M, Haller DG, Vaughn D, Giantonio B, Zimmer R, Petros WP, Stratford M, et al. 2003 Phase I trial of the antivascular agent combretastatin A4 phosphate on a 5-day schedule to patients with cancer: magnetic resonance imaging evidence for altered tumor blood flow. Journal of Clinical Oncology 21 4428-4438. (doi:10.1200/JCO.2003.12.986)

Stewart RJ, Farrell KW \& Wilson L. 1990 Role of GTP hydrolysis in microtubule polymerization: evidence for a coupled hydrolysis mechanism. Biochemistry 29 6489-6498. (doi:10.1021/ bi00479a022)

Strauss MP, Liew ATF, Turnbull L, Whitchurch CB, Monahan LG \& Harry EJ 2012 3D-SIM super resolution microscopy reveals a bead-like arrangement for FtsZ and the division machinery: implications for triggering cytokinesis. PLoS Biology 10 e1001389. (doi:10.1371/journal.pbio.1001389)

Szwedziak P, Wang Q, Bharat TAM, Tsim M \& Lowe J 2014 Architecture of the ring formed by the tubulin homologue FtsZ in bacterial cell division. eLife 3 e04601. (doi:10.1371/journal. pbio.1001389)

Takahara M, Takahashi H, Matsunaga S, Miyagishima S, Takano H, Sakai A, Kawano S \& Kuroiwa T 2000 A putative mitochondrial ftsZ gene is present in the unicellular primitive red alga Cyanidioschyzon merolae. Molecular and General Genetics 264 452-460. (doi:10.1007/ s004380000307)

Takahara M, Kuroiwa H, Miyagishima S, Mori T \& Kuroiwa T 2001 Localization of the mitochondrial FtsZ protein in a dividing mitochondrion. Cytologia 66 421-425. (doi:10.1508/cytologia.66.421)

Tan CM, Therien AG, Lu J, Lee SH, Caron A, Gill CJ, Lebeau-Jacob C, Benton-Perdomo L, Monteiro JM, Pereira PM, et al. 2012 Restoring methicillin-resistant staphylococcus aureus susceptibility to $\beta$-Lactam antibiotics. Science Translational Medicine 4 126ra35-126ra35. http://erc.endocrinology-journals.org

DOI: 10.1530/ERC-17-0118
(C) 2017 Society for Endocrinology Printed in Great Britain
Published by Bioscientifica Ltd 
TerBush AD, Yoshida Y \& Osteryoung KW 2013 FtsZ in chloroplast division: structure, function and evolution. Current Opinion in Cell Biology 25 461-470. (doi:10.1016/j.ceb.2013.04.006)

Thanedar S \& Margolin W 2004 FtsZ exhibits rapid movement and oscillation waves in Helix-like patterns in Escherichia coli. Current Biology 14 1167-1173. (doi:10.1016/j.cub.2004.06.048)

Tilney LG, Bryan J, Bush DJ, Fujiwara K, Mooseker MS, Murphy DB \& Snyder DH 1973 Microtubules: evidence for 13 protofilaments. Journal of Cell Biology 59 267-275. (doi:10.1083/jcb.59.2.267)

Van de Putte P, Van Dillewijn J \& Rörsch A 1964 The selection of mutants of Escherichia coli with impaired cell division at elevated temperature. Mutation Research 1 121-128. (doi:10.1016/00275107(64)90014-4)

van den Ent F 2001 Bacterial ancestry of actin and tubulin. Current Opinion in Microbiology 4 634-638. (doi:10.1016/S1369-5274(01)00262-4)

Vandecandelaere A, Brune M, Webb MR, Martin SR \& Bayley PM 1999 Phosphate release during microtubule assembly: what stabilizes growing microtubules. Biochemistry 38 8179-8188. (doi:10.1021/bi9830765)

Vaughan S, Wickstead B, Gull K \& Addinall SG 2004 Molecular evolution of FtsZ protein sequences encoded within the genomes of archaea, bacteria, and eukaryota. Journal of Molecular Evolution $\mathbf{5 8}$ 19-29. (doi:10.1007/s00239-003-2523-5)

Vitha S, McAndrew RS \& Osteryoung KW 2001 FtsZ ring formation at the chloroplast division site in plants. Journal of Cell Biology $\mathbf{1 5 3}$ 111-119. (doi:10.1083/jcb.153.1.111)

Walker RA, O'Brien ET, Pryer NK, Soboeiro MF, Voter WA, Erickson HP \& Salmon ED 1988 Dynamic instability of individual microtubules analyzed by video light microscopy: rate constants and transition frequencies. Journal of Cell Biology 107 1437-1448. (doi:10.1083/ jcb.107.4.1437)

Wang X \& Lutkenhaus J 1993 The FtsZ protein of Bacillus subtilis is localized at the division site and has GTPase activity that is dependent upon FtsZ concentration. Molecular Microbiology 9 435-442. (doi:10.1111/j.1365-2958.1993.tb01705.x)

Wang Y, Zhang H, Gigant B, Yu Y, Wu Y, Chen X, Lai Q, Yang Z, Chen Q \& Yang J 2016 Structures of a diverse set of colchicine binding site inhibitors in complex with tubulin provide a rationale for drug discovery. FEBS Journal 283 102-111. (doi:10.1111/febs.13555)

Ward JE \& Lutkenhaus J 1985 Overproduction of FtsZ induces minicell formation in E. coli. Cell 42 941-949. (doi:10.1016/00928674(85)90290-9)

Warner FD \& Satir P 1973 The substructure of ciliary microtubules. Journal of Cell Sciences 12 313-326.

White EL, Ross LJ, Reynolds RC, Seitz LE, Moore GD \& Borhani DW 2000 Slow polymerization of Mycobacterium tuberculosis FtsZ. Journal of Bacteriology 182 4028-4034. (doi:10.1128/JB.182.14.4028-4034.2000)

Yu X-C \& Margolin W 1997 Ca2+-mediated GTP-dependent dynamic assembly of bacterial cell division protein FtsZ into asters and polymer networks in vitro. EMBO Journal 16 5455-5463. (doi:10.1093/emboj/16.17.5455)

Yu XC \& Margolin W 1998 Inhibition of assembly of bacteria cell division protein FtsZ by the hydrophobic dye 5,5'bis-(8-anilino-1naphthalenesulfonate). Journal of Biological Chemistry 273 10216-10222. (doi:10.1074/jbc.273.17.10216)

Yutin N \& Koonin EV 2012 Archaeal origin of tubulin. Biology Direct 7 10. (doi:10.1186/1745-6150-7-10)

Received in final form 5 June 2017

Accepted 19 June 2017

Accepted Preprint published online 20 June 2017
() 2017 Society for Endocrinology Printed in Great Britain
Published by Bioscientifica Ltd. 